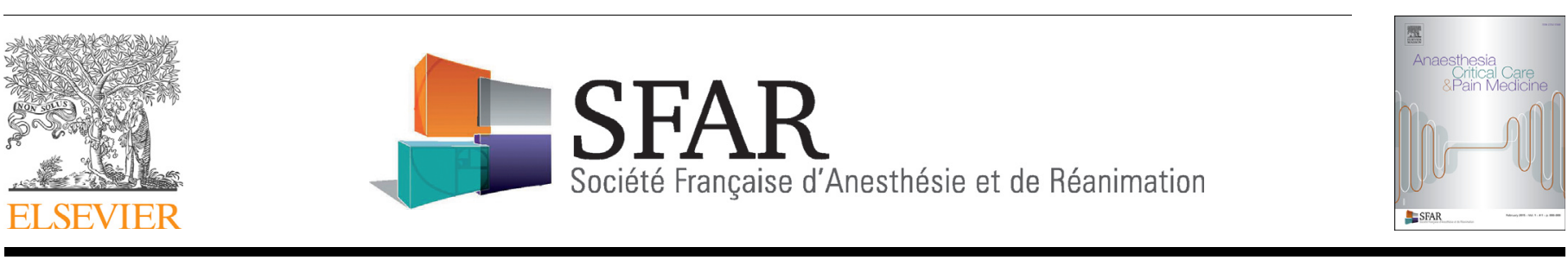

Guidelines

\title{
Diagnosis and management of heparin-induced thrombocytopenia ${ }^{\text {th }}$
}

\author{
Yves Gruel ${ }^{\mathrm{a}}$, Emmanuel De Maistre ${ }^{\mathrm{b}}$, Claire Pouplard ${ }^{\mathrm{c}}$, François Mullier ${ }^{\mathrm{d}}$, Sophie Susen ${ }^{\mathrm{e}, \mathrm{f}}$, \\ Stéphanie Roullet ${ }^{\mathrm{g}, \mathrm{h}, \mathrm{i}}$, Normand Blais ${ }^{\mathrm{j}}$, Grégoire Le Gal ${ }^{\mathrm{k}, \mathrm{l}}$, André Vincentelli ${ }^{\mathrm{m}}$, \\ Dominique Lasne $^{\mathrm{n}, \mathrm{o}}$, Thomas Lecompte ${ }^{\mathrm{p}}$, Pierre Albaladejo ${ }^{\mathrm{q}}$, Anne Godier ${ }^{\mathrm{r}, *}$, \\ Members of the French Working Group on Perioperative Haemostasis \\ (Groupe d'intérêt en hémostase périopératoire [GIHP])
}

\footnotetext{
a Laboratoire d'Hématologie-Hémostase, CHRU de Tours, Hôpital Trousseau, avenue de la République, 37044 Tours cedex 9, France

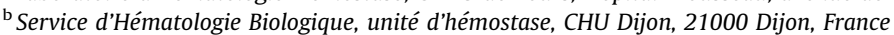

' Service d'Hématologie-Hémostase, Centre Régional de Traitement de l'Hémophilie, GICC EA 7501, Hôpital Trousseau, CHRU de Tours, avenue de la République, 37170 Chambray-lès-Tours, France

d Laboratoire d'hématologie-hémostase, Université catholique de Louvain, CHU UCL Namur, rue Dr-Gaston-Therasse 1, 5530 Yvoir, Belgium

e $\mathrm{CHU}$ Lille, Hematology Transfusion, Lille, France

${ }_{\mathrm{f}}^{\mathrm{f}}$ INSERM, U1011, University Lille, U1011-EGID, Institut Pasteur de Lille, Lille, France

${ }^{\mathrm{g}}$ Unité d'Anesthésie-réanimation uro-vasculaire et transplantation rénale, CHU de Bordeaux, place Amélie-Raba-Léon, 33076 Bordeaux, France

${ }^{\mathrm{h}}$ Service d'Anesthésie-Réanimation Tripode, CHU de Bordeaux, place Amélie-Raba-Léon, 33076 Bordeaux, France

i INSERM U 1034, Biologie des Maladies Cardiovasculaires, Université de Bordeaux, 1, avenue Magellan, 33600 Pessac, France

${ }^{\mathrm{j} S e r v i c e}$ d'hématologie et d'oncologie médicale, département de médecine, CHUM, 1000, rue Saint-Denis, H2X 0C1 Montréal, Canada

${ }^{\mathrm{k}}$ Division d'hématologie, Département de médecine, Université d'Ottawa, 501, rue Smyth, boîte 201A, Ottawa, ON K1H 8L6, Canada

${ }^{1}$ Institut de recherche, Hôpital d'Ottawa, 501 Smyth Rd, boîte 201A, Ottawa, ON K1H 8L6, Canada

${ }^{\mathrm{m}}$ Service de Chirurgie cardiaque, Institut Cœur Poumon, CHU de Lille, boulevard Pr-Leclercq, 59037 Lille, France

${ }^{\mathrm{n}}$ Laboratoire d'hématologie générale, Hôpital Necker, AP-HP, Paris, France

${ }^{\circ}$ Université Paris Sud Paris Saclay, Inserm U1176, Le Kremlin-Bicêtre, France

${ }^{\mathrm{p}}$ Hospital and academic departments of medicine, Hôpitaux Universitaires de Genève, rue Gabrielle-Perret-Gentil 4, 1205 Genève, Switzerland

q Pôle d'anesthésie-réanimation, CS10217, CHU Grenoble-Alpes, 38043 Grenoble cedex 9, France

${ }^{\mathrm{r}}$ Service d'anesthésie-réanimation, hôpital européen Georges-Pompidou, INSERM UMRS-1140, université Paris Descartes, 25, rue Leblanc, 75015 Paris, France
}

\section{Introduction}

Heparin-induced thrombocytopenia (HIT) is a rare, iatrogenic disease characterised by its potential severity, mainly related to thrombosis, and by difficulties regarding its diagnosis and management of affected patients. In 2002, a conference of experts mobilised by the French Society of Anaesthesia and Intensive Care Medicine (Société française d'anesthésie et de réanimation [SFAR]) drafted recommendations for the management of HIT [1]. Since then, the drugs available to treat patients have evolved: lepirudin has disappeared, the prescription of fondaparinux and direct oral anticoagulants has increased, and finally the biological tests required for diagnosis are more effective. These developments have led the French Working on Perioperative Haemostasis (Groupe d'intérêt en hémostase périopératoire [GIHP]) and the French Study Group on Thrombosis and Haemostasis (Groupe d'étude sur l'hémostase et la thrombose [GFHT]), in collaboration with the French Society of Anaesthesia and Intensive Care

\footnotetext{
Proposal from the French Working on Perioperative Haemostasis (Groupe d'intérêt en hémostase périopératoire [GIHP]) and the French Study Group on Thrombosis and Haemostasis (Groupe d'étude sur l'hémostase et la thrombose [GFHT]), in collaboration with the French Society of Anaesthesia and Intensive Care Medicine (Société française d'anesthésie et de réanimation [SFAR]).

* Corresponding author.

E-mail address: anne.godier@aphp.fr (A. Godier).
}

Medicine (Société française d'anesthésie et de réanimation [SFAR]) to define updated proposals for the diagnosis and care of HIT.

Since 2002, many articles have been published, but with few large patient series and even fewer randomised trials comparing available treatments. The level of evidence of the available studies remains uncertain and the level of recommendation is therefore quite low, explaining that our group has decided, as in 2002, not to assign a grade to the proposals issued. We have adopted a different attitude from that of the American College of Chest Physicians (ACCP) [2] or the British [3], which in 2012 proposed strong recommendations.

The methodology used to develop these proposals was as follows: the issues addressed were assigned to several working groups, composed of members of the GIHP and/or the GFHT. A first text incorporating updated data from the literature and recommendations or guidelines from UK [3], ACCP [2] and more recently issued by ASH [4] was written based on the 2002 expert conference [1]. This first text was then reviewed, discussed and modified by the other groups, and then submitted for critical analysis by other GIHP and GFHT members. Finally, these proposals were validated by a vote ( $n=32$ participants), thus determining the strength of each proposal. To retain a proposal, at least $50 \%$ of members had to express their agreement (for a strong agreement, the threshold was set at $70 \%$ ), while less than $20 \%$ of them could express their opposition. In the absence of agreement, the proposals were reformulated and put to a new vote in order to obtain a better agreement. These proposals were developed in collaboration with the SFAR Clinical Referential Committee. 
Finally, our text addresses the following 12 questions and presents 40 proposals useful for clinical practice:

- What are the different stages and levels of risk of HIT?

- Which platelet count monitoring for HIT detection during heparin therapy?

- What are the circumstances that should be considered when diagnosing HIT?

- Apart from HIT, what are the other possible aetiologies of thrombocytopenia in a patient treated with heparin?

- Which biological tests are needed to confirm the diagnosis of HIT?

- What is the practical approach for the diagnosis and initial management of HIT in the acute phase?

- What are the alternative anticoagulants that can be used in HIT after stopping heparin?

- Is there a place for other treatments in a patient with suspected HIT?

- Which treatment should be proposed for HIT in surgical settings outside cardiac surgery?

- Which treatment should be proposed for cardiac surgery with and without extracorporeal circulation (ECC) in the case of HIT?

- Which treatment should be proposed for HIT in a medical setting?

- Which prevention can be proposed to avoid the occurrence of HIT or recurrence?

\section{General information}

Two types of thrombocytopenia may occur in patients treated with heparin, unfractionated heparin (UFH) or low molecular weight heparin (LMWH):

- a benign thrombocytopenia (type I), of non-immune origin and early onset, without thrombotic complications and regresses despite continued heparin therapy;

- a more severe thrombocytopenia (type II), which is most often moderate, of delayed onset, immune and potentially very severe since associated with thrombosis. It alone can be qualified as HIT and is the subject of these proposals.

HIT is a clinical-biological syndrome induced by IgG isotype antibodies, which almost always recognise heparin-modified platelet factor $4(\mathrm{PF} 4 / \mathrm{H})$ [5], with intense platelet activation associated with explosive thrombin generation that can lead to venous and/or arterial thrombosis [6,7]. Thrombocytopenia results from massive activation of platelets and from their elimination by the mononuclear phagocyte system, the cells being sensitised by $\mathrm{PF} 4 /$ heparin/IgG complexes. Thrombosis is the consequence of a multi-cellular activation involving platelets with the release of procoagulant microparticles, endothelial cells, neutrophils and especially monocytes that express tissue factor contributing to the hypercoagulability of patients [8].

The diagnosis of acute HIT is difficult since there are often other potential causes of thrombocytopenia, particularly in the postoperative period or in ICU patients, and it must integrate clinical circumstances and associated treatments. It is important not to neglect this diagnosis, or conversely not to wrongly conclude that HIT is present because the systematic discontinuation of heparin in the presence of any thrombocytopenia poses therapeutic problems and may expose the patient to complications.

Biological confirmation of the diagnosis is necessary in all cases but often takes several days. However, biological assays, looking for anti-PF4 antibodies, must never delay the stopping of heparin and the prescription of an alternative anticoagulant.
The thrombotic risk is considered high during the first month after diagnosis [9], the antibody titre and their ability to activate platelets and haemostasis decreasing thereafter, to no longer be detectable in good standing beyond three months [10].

Question 1: What are the different stages and level of risk of TIH?

Proposal \# 1

It is proposed to distinguish three different stages of HIT according to its ancientness:

- acute HIT, which is a recent HIT, diagnosed within the last month, during which time antiplatelet factor 4 (PF4) activating antibodies are most often present with a high thrombotic risk;

- subacute HIT, which corresponds to HIT diagnosed 1 to 3 months ago, during which time anti-PF4 antibodies are often present with a low titre;

- previous history of HIT, which corresponds to an old HIT of more than 3 months, and at this stage, anti-PF4 antibodies are most often undetectable.

(STRONG AGREEMENT)

Proposal \# 2

It is proposed to define the level of risk of HIT during heparin administration as:

- low (less than 0.1\%) during treatments with low molecular weight heparin (LMWH) in medicine (except cancer), obstetrics (except surgery including caesarean section), or in the course of minor trauma; during all fondaparinux treatments; during isolated non-fractionated heparin (UFH) injection for endovascular procedure or simple surgery; during any treatment by UFH or LMWH lasting beyond one month;

- intermediate (between 0.1 and $1 \%$ ) in case of prophylactic treatment with UFH in medicine/obstetrics, or with LMWH in a cancer patient, or a severe trauma patient, or a patient treated with LMWH in postoperative care (including cardiac surgery);

- high (above 1\%) in the case of prophylactic treatment with UFH in surgery, (including circulatory assistance) or for renal replacement therapy; in the case of all curative treatments with UFH in medicine/surgery/ obstetrics.

(STRONG AGREEMENT)

\section{Rationale}

The management of patients depends on the age of HIT and the persistence or otherwise of circulating anti-PF4 antibodies. Three different stages can be individualised (Proposal No. 1).

The risk of HIT varies according to the type of heparin administered (UFH or LMWH), the underlying conditions, and the duration of treatment (Table 1 ).

In 2012, the ACCP had defined its proposals taking into account only two levels of risk, higher or lower than 1\% [2]. In 2018, the ASH proposed three levels of risk, high $(>1 \%)$, intermediate (between 0.1 and $1 \%)$ and low $(<0.1 \%)$ [4], a position we chose to adopt, as it better responds to the different situations with which the clinician is most frequently confronted. 
Table 1

Risk of HIT by context and type of heparin administered.

\begin{tabular}{|c|c|c|c|c|c|}
\hline & \multirow[t]{2}{*}{ Context } & \multirow[t]{2}{*}{ Dose } & \multicolumn{3}{|c|}{ Level of risk } \\
\hline & & & Low & Intermediate & High \\
\hline \multirow[t]{4}{*}{ UFH } & Surgery including caesarean section & $\begin{array}{l}\text { Prophylactic or } \\
\text { Curative }\end{array}$ & & & + \\
\hline & $\begin{array}{l}\text { Medical/ } \\
\text { Obstetrical }\end{array}$ & Curative & & & + \\
\hline & Renal and cardiac assistance (СРB, ECMO ...) & & & & + \\
\hline & $\begin{array}{l}\text { Medical/ } \\
\text { Obstetrical }\end{array}$ & Prophylactic & & + & \\
\hline \multirow[t]{3}{*}{ LMWH } & Surgery including caesarean section & $\begin{array}{l}\text { Prophylactic or } \\
\text { Curative }\end{array}$ & & + & \\
\hline & Cancer & & & + & \\
\hline & $\begin{array}{l}\text { Medical/ } \\
\text { Obstetrical }\end{array}$ & $\begin{array}{l}\text { Prophylactic or } \\
\text { Curative }\end{array}$ & + & & \\
\hline
\end{tabular}

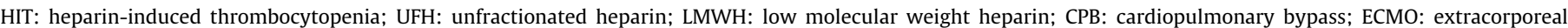
membrane oxygenation.

The risk of HIT is assessed as low during all medical treatments with LMWH (except cancer), and during pregnancy outside the surgical context. This risk is also very low or even non-existent under fondaparinux (which is not strictly speaking a heparin) whether prescribed with preventive or curative doses [11].

In medicine, a prospective study in 2005 found an incidence of HIT equal to $0.8 \%$ under LMWH at preventive or curative doses [12], but this result has not been confirmed. Another study in 2011, involving more than 25,000 patients, found a much lower frequency of HIT $(\leq 0.2 \%)$ in medical patients treated with a preventive dose of LMWH [13]. We therefore do not propose any monitoring of platelets in medical patients under LMWH (question 2 ), in accordance with the most recent British [3] and North American [4] recommendations.

In addition, a patient receiving a single bolus of UFH (especially for endovascular examination) is also at low risk of HIT, unless he or she has recently (within the previous 3 months) been exposed to heparin for several days in a row.

In obstetrics, a systematic review of more than 2700 pregnancies under LMWH confirmed a very low risk of HIT, less than $0.1 \%$ [14], also justifying the lack of platelet monitoring in this context.

Finally, the risk of HIT is very low in all patients after one month of heparin treatment, regardless of the molecule administered (UFH or LMWH) and the dosage.

The risk of HIT is intermediate (between 0.1 and 1\%) in many clinical situations. This is particularly the case for patients treated for prophylaxis with LMWH in a surgical setting, and for whom the risk of HIT is estimated to be almost 10 times lower than with UFH $[15,16]$.

However, it varies greatly depending on the context and type of surgery, as evidenced by this wide range of incidence, from 0.1 to $1 \%$, and which does not necessarily implicate the same monitoring. Thus, the risk of HIT considered as low in case of minor trauma [4] appears to be higher under LMWH after surgery for severe trauma [17], being estimated at $0.36 \%$ [18]. However, it is much lower after scheduled orthopaedic surgery, such as hip or knee replacement [19]. In France, minor surgery is not an indication in itself for drug prophylaxis, and we have therefore considered any surgical procedure treated with LMWH to be at intermediate risk of HIT.

In cardiovascular surgery, despite a bolus of UFH performed intraoperatively, particularly in the case of cardiopulmonary bypass (CPB) surgery, the risk of HIT is reduced if LMWH is prescribed postoperatively $(0.4 \%$ versus $2.5 \%$ under $\mathrm{UFH})$ $[20,21]$. The risk of HIT in cardiovascular surgery patients under LMWH is therefore considered to be at intermediate risk.

In medical cancer patients, only one study reported a high incidence $>1 \%$ of HIT [12], but its methodology was controversial
[2], and this result was not confirmed [22], which is why we considered the risk of HIT in this context as intermediate.

A high risk of HIT (greater than 1\%) exists for the majority of patients treated with UFH, whether they receive a preventive or curative dose, particularly in orthopaedic surgery [23], or after cardiac surgery with CPB [24].

In medical patients, the risk of UFH-related HIT is probably lower but remains close to $1 \%[13,25,26]$ and higher during curative intravenous treatments [13,27].

Patients on extracorporeal membrane oxygenation (ECMO) require curative anticoagulant treatment with intravenous UFH and therefore have a high risk of HIT [28], although still poorly defined $[29,30]$.

\section{Question 2: Which platelet count monitoring for HIT detection in heparin-treated patients?}

Proposal \#3

It is proposed that all patients treated with heparin, whether unfractionated or low molecular weight, should have a systematic platelet count before initiation of treatment (or alternatively as soon as possible after the first injection, before D4).

(STRONG AGREEMENT)

Proposal \#4

It is proposed not to monitor platelet count in patients at low risk of HIT.

(STRONG AGREEMENT)

Proposal \#5

For patients at intermediate risk of HIT, it is proposed to monitor platelet counts once to twice a week from day 4 to day 14 of treatment, and then once a week for one month if heparin therapy is continued.

(STRONG AGREEMENT)

Proposal \#6

For patients at high risk of $\mathrm{HIT}$, it is proposed to monitor platelet counts two to three times a week from day 4 to day 14 of treatment, and then once a week for one month if heparin therapy is continued.

(STRONG AGREEMENT) 
Rationale

The early diagnosis of HIT

The early diagnosis of HIT depends primarily on monitoring platelet count (NP).

A first platelet count (PC) is recommended before starting any heparin treatment [2,3], or alternatively as soon as possible (before the 4 th day of treatment), the result obtained serving as a reference (Proposal No. 3).

\section{The monitoring then depends on the level of HIT risk}

In all situations where the risk of HIT is low, no monitoring of PC is required (Proposal \#4), but a blood count will be performed during any unusual or unexpected event (see question \#3, Proposal \#7).

Control of PC is necessary for other patients, with a more sustained rhythm for those with a high risk ( 2 or 3 times a week). It should be noted that the ASH proposes in this case a PC check every 48 hours [4], which may be preferred if the risk is very high, as for example during cardiac surgery in a patient with a previous history of HIT.

However, after cardiac surgery with $\mathrm{CPB}$, repeated monitoring of the PC allows a careful analysis of the postoperative evolution and the identification of a possible "biphasic" profile, characterised by a decrease in the PC in the days following a phase of total or partial correction, and which is highly predictive of an HIT $[21,31]$.

A monitoring window the day 4 to day 14 of treatment is proposed, as the vast majority of HIT occur during this period [10]. However, a few cases have been reported after 15 days of treatment, particularly with LMWH [32], but never after one month. It is therefore logical to maintain monitoring of platelets for one month, but with a lower frequency after 15 days of treatment. Beyond that, the risk of HIT becomes very low and no control of PC is necessary.

Question 3: What are the circumstances that should evoke the diagnosis of HIT?

\section{Proposal \# 7 \\ Whatever the risk of HIT, it is proposed to systematically monitor the platelet count of any patient treated with heparin in the event of an unexpected clinical event: onset or aggravation of venous or arterial thrombosis, skin necrosis or unusual reaction after heparin injection (chills, low blood pressure, dyspnea, amnesia...)}

\section{(STRONG AGREEMENT)}

Rationale

Two particularities characterise HIT:

- the chronology of thrombocytopenia in relation to heparin administration;

- the rarity of haemorrhagic manifestations and the frequency of venous and/or arterial thrombotic events.

Thrombocytopenia or a sharp and sudden decrease in platelet count typically occurs between days 5 and 14 of heparin therapy. However, this delay may be shorter (before 5 days), or even as early as the first day of treatment in patients who have been recently exposed to heparin in the previous 3 months [10]. It may also be longer, especially with LMWH, and may exceed 3 weeks [32].

The diagnosis should be made in the presence of a platelet count $<100 \mathrm{G} . \mathrm{L}^{-1}$ and/or a decrease in the platelet count $>50 \%$ compared to a previous value, most often obtained at the beginning of treatment. Thrombocytopenia is typically moderate, ranging from 30 to $70 \mathrm{G} . \mathrm{L}^{-1}$ in $80 \%$ of patients.

Consumption coagulopathy (DIC) is also possible and does not exclude the diagnosis of HIT. It actually aggravates thrombocytopenia. In intensive care patients or in the postoperative period, the coexistence of other pathologies (sepsis, haemorrhages, massive transfusions, DIC...) can also lead to deeper thrombocytopenia.

More rarely, thrombotic complications may occur in the absence of thrombocytopenia, but there is almost always a relative decrease in platelet count.

The existence of venous and/or arterial thrombotic events under heparin is very suggestive of HIT. Deep vein thrombosis affects up to $50 \%$ of patients, which justifies for some clinicians their systematic search by a Doppler ultrasound examination of the lower limbs in case of suspicion [33]; pulmonary embolism occurs in 10 to $25 \%$ of cases.

Arterial thrombosis is the most typical event, although less frequent. All territories can be affected, but more frequently abdominal aorta and its branches.

Venous gangrene in the limbs is very rare, and can complicate HIT when treatment with a vitamin $\mathrm{K}$ antagonist (VKA) has been initiated without being combined with another effective antithrombotic agent [34], or if HIT is diagnosed at the time of a heparin/VKA relay.

The classic heparin resistance with an extension of the initial thrombotic process is also a possible but rare discovery circumstance.

Neurological complications occur in approximately $10 \%$ of patients, with ischemic stroke, cerebrovascular thrombosis, confounding conditions or transient amnesia occurring in decreasing order of frequency.

Other clinical manifestations that may lead to the suspicion of HIT are rare: cutaneous necrosis at heparin injection sites is most typical $[11,35,36,111]$ and can be inaugural, preceding the drop in platelet count; cutaneous erythema is also possible, but not definitely related to HIT, particularly with LMWH [37], is exceptional.

Haemorrhagic complications are also rare, as well as haemorrhagic necrosis of the adrenals, which are promoted by DIC and associated with higher mortality.

An unusual reaction after injection of heparin has sometimes been reported, particularly in the context of haemodialysis; hypotension, chills, anaphylactic reaction.

All clinical manifestations and data on the evolution of platelet count can be analysed to define a pre-test diagnostic probability score, which can help in the prescription of biological analyses, and $4 \mathrm{~T}$ is the most widely used in clinical practice (question \# 4).

\section{Question 4: What are the other possible causes of thrombocytopenia in a patient on heparin and how to define the clinical probability of HIT?}

\section{Proposal \# 8}

In case of suspicion of HIT, it is proposed to define the clinical probability of HIT using the 4T score, outside a cardiac surgery context.

(STRONG AGREEMENT)

\section{Rationale}

Heparin thrombocytopenia is often due to potential causes other than HIT that should be identified

1. Under UFH, early and moderate thrombocytopenia may occur within the first two days of treatment, resulting from a direct pro- 
aggregating effect of UFH. However, it may also exceptionally reflect early HIT after reintroduction of heparin in a patient sensitised by heparin therapy within the previous 3 months.

2. Other causes of isolated thrombocytopenia are possible, particularly in the intensive care patient [38] or after surgery:

- perioperative haemodilution and platelet consumption in extracorporeal circuits or counterpulsion with an intra-aortic balloon are clinical circumstances that are most often easily identified;

- consumption thrombocytopenia is also common at the end of cardiac surgery, in the case of ventricular assistance, or extrarenal epuration, all of which are at significant risk of HIT;

- post-transfusion purpura, linked to alloimmunisation, should also sometimes be considered (typically major and sudden decrease in platelets and haemorrhagic context). Its diagnosis is urgent given the risk of severe bleeding and the need for specific treatment;

- the use of GPIIb-IIIa glycoprotein inhibitors in acute coronary syndromes is potentially complicated by early and often profound thrombocytopenia;

- the imputability of other drugs potentially responsible for immune thrombocytopenia in intensive care [39] or certain antimitotic chemotherapies is also to be mentioned.

3. When thrombocytopenia is associated with venous or arterial thrombotic complications, other aetiologies than HIT should be considered. These are mainly antiphospholipid syndrome [40], thrombotic thrombocytopenic purpura and DIC. Thrombocytopenia and thrombosis can also be observed in patients with cancer, with a clinical picture of pseudo-HIT.

Potential causes of thrombocytopenia other than HIT will therefore be considered in assessing the clinical probability of HIT.

The clinical probability of HIT is assessed by the 4 T score

The clinical probability of HIT is assessed by the 4T score $[2,41]$, based on four major criteria and 0,1 or 2 points are assigned for each of them (Fig. 1).

The 1st T depends on the number of platelets at the time of suspicion (thrombocytopenia)

Thrombocytopenia is generally never profound (often between 30 and $70 \mathrm{G} / \mathrm{L}$ ) and remains $>20 \mathrm{G} / \mathrm{L}$. In addition, an authentic HIT can be observed without actual thrombocytopenia, but a decrease in platelet count of at least 50\% from the highest count before suspicion is highly predictive ( 2 points). On the contrary, a drop of less than $30 \%$ in the PC or a PC $<10 \mathrm{G} / \mathrm{L}$ is not in favour of HIT (0 point).

The 2nd T depends on the time of onset of thrombocytopenia (Timing)

In typical cases, a decrease in platelet count is observed 5 to 10 days after initiation of heparin therapy ( 2 points) or earlier if heparin therapy has been administered within the previous 3 months (1 point).

The 3rd T depends on the presence or absence of venous and arterial thromboembolic events or other clinical events associated with thrombocytopenia (thrombosis)

Thrombotic complications are sometimes obvious, but some thromboses may be asymptomatic. Some practitioners have therefore suggested that they should be systematically researched by a Doppler ultrasound examination of the lower limbs [4].
The 4th T depends on whether or not there is another potential cause of thrombocytopenia (other)

This aspect is the most difficult to evaluate because patients often have associated pathologies (sepsis, liver disease. . .) and treatments (chemotherapy, antibiotics, diuretics...) that are potentially a cause of thrombopenia. Another acute haematological pathology must always be sought and rigorous analysis of the blood count is therefore necessary. Antiplatelet alloimmunisation should also be considered in the case of recent administration of labile blood products. However, non-heparin-related transfusional or drugrelated thrombocytopenia is often more severe than that associated with HIT, and complicated by bleeding and not thrombosis.

Each item in the $4 \mathrm{~T}$ being scored from 0 to 2, the total score may reflect a low probability of HIT if it is $\leq 3$, intermediate if it is equal to 4 or 5 or high if it is $\geq 6$.

In patients who have undergone cardiac surgery with $\mathrm{CPB}$, this score is more difficult to apply and the analysis of the postoperative evolution profile of platelet count is more efficient. Indeed, a "biphasic" evolution profile of platelet count is equivalent to a $4 \mathrm{~T}$ score $\geq 6$, with a high probability of HIT [21,42]. In intensive care patients with multiple pathologies, the $4 \mathrm{~T}$ score is also difficult to assess due to co-morbidities and multiple treatments, and can be thus compromised [43].

\section{Question 5: What are the biological tests to be performed when there is a suspicion of HIT?}

Proposal \# 9

In case of suspicion, it is proposed to look for anti-PF4 antibodies as soon as possible if the clinical probability of HIT is intermediate or high.

(STRONG AGREEMENT)

Rationale

The discovery of thrombocytopenia in a patient treated with heparin should be systematically controlled by examining the sample tube for a clot and the smear to exclude the presence of aggregates. A new citrate sample often ruled out false thrombocytopenia on EDTA.

Simple haemostasis tests (PT, aPTT, fibrinogen, D-dimers or fibrin monomers) should also be prescribed in order to look for DIC, possible in some severe HIT and therefore not excluding this diagnosis.

Two categories of specific tests can be used to identify antibodies associated with HIT [44], each with advantages and disadvantages.

\section{Immunological tests}

Immunological tests detect antibodies of the IgG, IgM, IgA isotype specifically directed against modified PF4. They are semiquantitative (ELISA or chemiluminescent tests) or qualitative (agglutination, immunofiltration, immunoturbidimetry...), have excellent sensitivity and are easy to carry out. These tests should be performed as soon as possible to quickly rule out the diagnosis of HIT and guide the clinician towards finding another aetiology of thrombocytopenia. Their negative predictive value is excellent [45], but their specificity is less good since anti-PF4 antibodies can appear without being associated with HIT, particularly after cardiac surgery, after which they are present in nearly one out of two patients. The specificity and especially the positive predictive value (PPV) of immunoassay can however be improved by using a method that specifically detects IgG antibodies and expresses the result quantitatively, most often by specifying the measured absorbance value [46]. Another approach is to test whether a high 


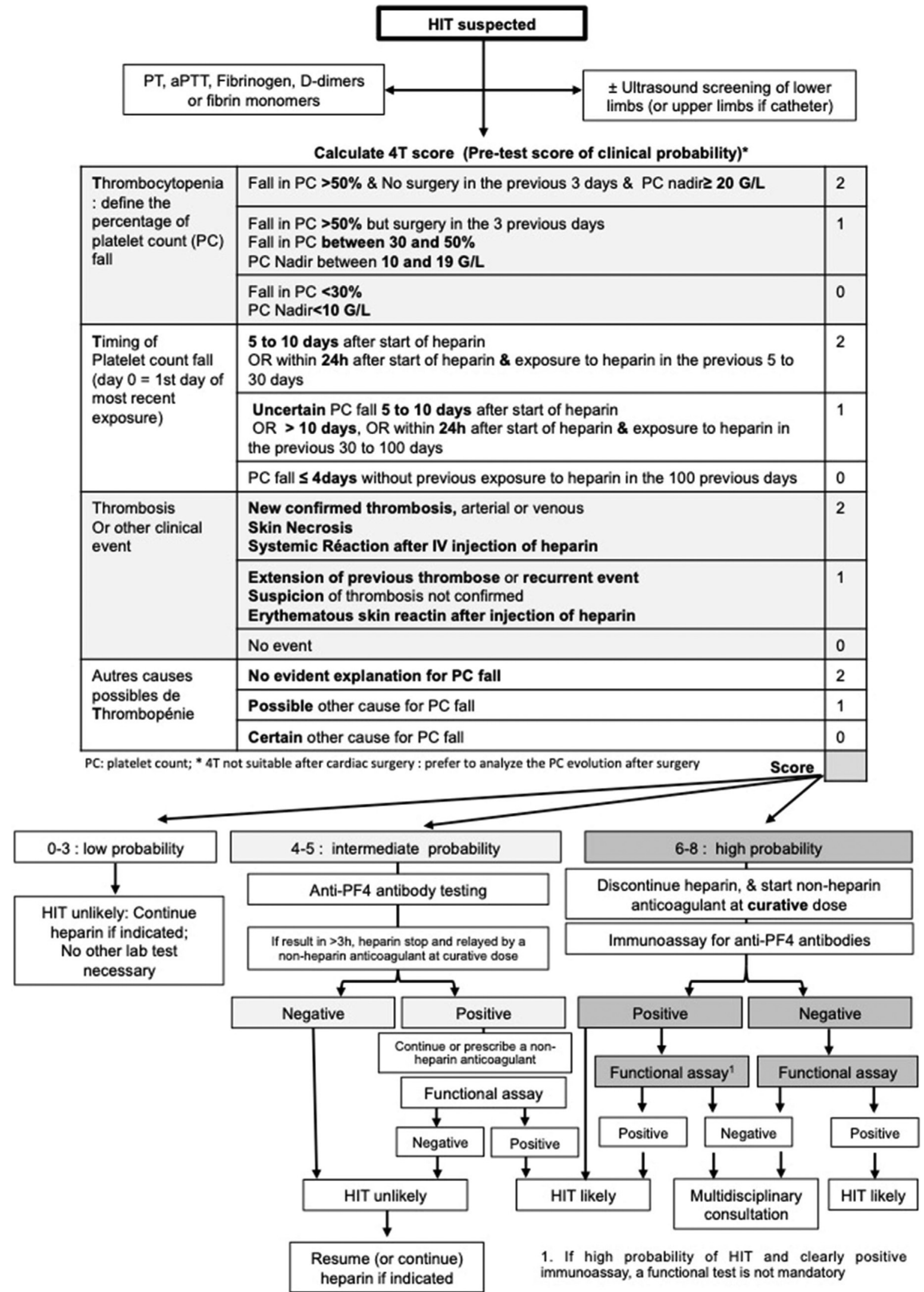

Fig. 1. Algorithm of clinical and biological diagnosis of heparin-induced thrombocytopenia (HIT). 
concentration of heparin decreases the absorbance measured in ELISA, this result being specific for anti-PF4 antibodies associated with HIT [47]. However, this procedure, which is recommended for low levels of antibodies (OD $<1$ ) [48], is rarely applied and its usefulness is controversial [49].

\section{Functional or platelet activation tests}

Functional or platelet activation tests show the presence in the patient's plasma or serum of IgG isotype antibodies capable of activating the platelets of a control subject in the presence of heparin [50].

These tests can be performed on platelet-rich plasma, such as platelet aggregation tests (PAT), or after washing platelets, which sensitises the detection of activating antibodies. In the latter case, a distinction is made between the radiolabelled serotonin release test or SRA, which is considered a "gold standard" test, and the HeparinInduced Platelet Activation (HIPA) test, which is rarely used in France. The search for heparin-dependent antibodies can also be performed on whole blood using an impedance technique [51]. Nevertheless, tests carried out on washed platelets are still considered as the most sensitive methods with specificity close to $100 \%$. The use of platelets from several controls and/or selected controls increases the performance of functional tests, including platelet aggregation tests (PAT).

The SRA (requiring the use of carbon 14) and HIPA tests are long and delicate, and are reserved for a few expert laboratories. Other approaches such as flow cytometry have been adapted for the biological diagnosis of HIT [50] but have been little used and have yet to be validated.

\section{Question 6: What is the initial management of a patient with suspected TIH?}

\section{Proposal \#10}

If the pre-test probability is low $(4 \mathrm{~T} \leq 3)$, diagnosis of HIT can be excluded and treatment with heparin can be continued without specific bioassays. The search for an aetiology of thrombocytopenia with close monitoring of platelet count must be carried out.

\section{(STRONG AGREEMENT)}

Proposal \#11

If the pre-test probability is intermediate $(4 T=4$ or 5$)$ or high $(4 T \geq 6)$, biological tests must systematically be performed to detect anti-PF4 antibodies.

(STRONG AGREEMENT)

\section{Proposal \#12}

If the clinical probability is intermediate and the search for anti-PF4 antibodies is negative, the diagnosis of HIT is excluded and heparin therapy can be continued or resumed, with close monitoring of platelet count.

(STRONG AGREEMENT)

\section{Proposal \#13}

When the clinical probability of HIT is high (4T $\geq 6$ or ECC with biphasic platelet count progression profile), heparin therapy should be stopped immediately and replaced by nonheparin anticoagulant therapy with curative doses, without waiting for the results of biological tests.

(STRONG AGREEMENT)

\section{Proposal \#14}

If the clinical probability is intermediate or high and a significant titre of anti-PF4 antibodies is detected, a functiona test should be performed. If positive, the diagnosis of HIT is confirmed.

(STRONG AGREEMENT)

\section{Rationale}

The management of suspected HIT is based on a concerted and rapid clinical and biological approach, which is critical to the management of antithrombotic therapy and to the patient's prognosis.

The first step is to define the clinical probability of HIT, especially with the 4T score, and if it is low, another aetiology of thrombocytopenia should be investigated without specific biological analyses in accordance with the British [3] and ASH [4] proposals. However, a testing for anti-PF4 antibodies may be discussed for patients where the $4 \mathrm{~T}$ is difficult to define, especially in the case of missing data.

In other cases (intermediate or high clinical probability), a blood sample for the detection of anti-PF4 antibodies should be collected as soon as possible.

Essential point: the decision to discontinue heparin and replace it with another immediate antithrombotic should not be delayed by waiting for the laboratory results.

Immunological tests are performed as first-line tests and a functional test is performed only if the detection of anti-PF4 antibodies is positive, especially in cases where the pre-test probability is intermediate.

In case of a high pre-test probability, associated with the presence of a relatively high titre of anti-PF4 antibodies in ELISA (e.g. OD greater than 2), the diagnosis of HIT can be confirmed without the need for a functional test [4,52]. However, this approach is only applicable if anti-PF4 antibodies are tested by quantitative immunological tests. When $4 \mathrm{~T}$ is high, a functional test is recommended if the immunological search for anti-PF4 antibodies is negative, as rare HIT cases with anti-IL8 antibodies have been reported [53].

When the clinical probability is intermediate and the laboratory can perform an immunological or functional test with a short response time ( $<3$ hours after sampling), the clinician may consider waiting for the results before modifying the anticoagulant treatment (Fig. 1).

For any suspicion of HIT, it is important to achieve a clear diagnostic conclusion that takes into account all the information in the file and it is mandatory to report each case to the Regional Pharmacovigilance Centre.

In conclusion, the diagnosis of HIT requires a concerted effort between clinicians and biologists, particularly in view of the immediate (choice of antithrombotic treatment) and secondary (possibility of a subsequent prescription of an antithrombotic treatment) issues.

Question 7: What are the alternative anticoagulants that can be used in HIT after stopping heparin? How to prescribe them in the acute phase?

Proposal \# 15

Anticoagulants for use in the acute phase of HIT include argatroban, bivalirudin, danaparoid, and fondaparinux, and direct oral anticoagulants.

(STRONG AGREEMENT) 
Proposal \# 16

Danaparoid is not recommended as a first-line treatment for HIT in severe renal failure.

(STRONG AGREEMENT)

\section{Proposal \# 17}

Prophylactic doses of danaparoid are not recommended for the treatment of acute HIT. Curative IV doses are more effective and necessitate the monitoring of anti-Xa activity (with a specific calibration curve).

(STRONG AGREEMENT)

\section{Proposal \# 18}

If the platelet count is not corrected, or if a thrombosis under danaparoid appears or spreads, it should be replaced by another anticoagulant.

(STRONG AGREEMENT)

\section{Proposal \# 19}

It is proposed to use argatroban as a priority for the treatment of HIT in severe renal failure. This anticoagulant is contraindicated in severe liver failure (Child-Pugh C). It must be used in a specialised structure.

(STRONG AGREEMENT)

\section{Proposal \# 20}

It is proposed that the initial dose of argatroban be $1 \mu \mathrm{g} / \mathrm{kg} /$ min and reduced to $0.5 \mu \mathrm{g} / \mathrm{kg} / \mathrm{min}$ in patients with resuscitation, cardiac surgery and moderate hepatic failure (Child-Pugh B).

(STRONG AGREEMENT)

\section{Proposal \# 21}

Biological monitoring of argatroban treatment should be applied daily. It may be based on aPTT (if normal before treatment) to maintain between 2 and 3 times the control value, or preferably on other more specific assays such as diluted thrombin time or ecarin test (proposed therapeutic window $=0.5$ to $1.5 \mu \mathrm{g} / \mathrm{mL}$ ).

(STRONG AGREEMENT)

\section{Proposal \# 22}

It is recommended that $A V K$ be prescribed for the acute phase of HIT only when platelet count is corrected (>150 G/L) as a supplement to parenteral treatment.

(STRONG AGREEMENT)

\section{Proposal \# 23}

In acute HIT

1. In a stable patient with no severe renal or hepatic impairment and no risk of bleeding (absence of comorbidity or recent or expected invasive procedure in the short-term), all available non-heparin anticoagulants can be prescribed, but the simplicity of use of fondaparinux and DOACs (without specific biological monitoring) justifies that they can be proposed as first-line alternative treatments, of after the use of danaparoid or argatroban.

2. In an unstable patient, or a patient at risk of bleeding (comorbidity or recent or planned invasive procedure in the short-term), or in intensive care units, it is proposed to prescribe as a priority an injectable anticoagulant of $1 / 2$ short life, argatroban or bivalirudin, combined with strict biological monitoring.

3. In a patient with severe HIT (massive PE, extensive or arterial thrombosis, venous gangrene, coagulopathy of consumption), it is proposed to prescribe argatroban or bivalirudin as a priority injectable treatment combined with strict biological monitoring.

4. In a patient with severe renal impairment (creatinine clearance $<30 \mathrm{~mL} / \mathrm{min}$ ), only argatroban can be used.

5. In a patient with severe hepatic impairment (Child-Pugh C), bivalirudin, danaparoid or fondaparinux may be used.

(STRONG AGREEMENT)

\section{Rationale}

Danaparoid sodium has long been the most commonly prescribed antithrombotic agent to relay heparin in cases of suspected HIT. Then, it was possible to use lepirudin, a direct antithrombin molecule, but this drug is no longer available in France since 2012. In recent years, argatroban, another synthetic antithrombin agent, fondaparinux and, more recently, direct oral anticoagulants (DOACs) have flourished. The use of the latter two drugs, although not officially authorised in HIT, is increasingly being proposed [4]. Bivalirudin, which has also been widely used in several countries, is no longer available in France today, but generics are expected to be available soon. Finally, vitamin $\mathrm{K}$ antagonists (VKAs) are potentially dangerous in the acute phase of HIT.

\section{Danaparoid sodium}

1. Danaparoid sodium is an extraction heparinoid (derived like several LMWH from pig intestine) that contains heparan sulfate, dermatan sulfate and chondroitin sulfate. Its anticoagulant activity is mainly related to its anti-Xa activity, associated with a low antiIla activity. It does not prolong prothrombin time and does not usually increase the aPTT. The elimination half-life of the danaparoid's anti-Xa activity is long, about 25 hours. The anti-Ia activity is shorter, about 7 hours, but it is longer in case of renal failure, a situation where argatroban is preferable. The labelled indications of danaparoid include the prophylactic and curative treatment of thromboembolic events in patients with HIT or a documented history of HIT. This drug is the oldest used in the treatment of HIT [47] although it has been evaluated in only one randomised trial [54] and two retrospective historical cohorts $[55,56]$.

2. Danaparoid sodium can be administered subcutaneously ( 2 or 3 injections/day) or continuously intravenously, usually preceded by a bolus. The dosage varies according to the clinical, medical or surgical situation and protocols adapted to each situation have been established.

When used intravenously with curative doses, danaparoid is prescribed with an intravenous loading dose that varies by weight (1250 U IV if weight $\leq 55 \mathrm{~kg} ; 2500 \mathrm{U}$ IV if $55<$ weight $\leq 90 \mathrm{~kg}$; $3750 \mathrm{U}$ IV if $>90 \mathrm{~kg}$ ) and a continuous intravenous maintenance dose of $400 \mathrm{U} / \mathrm{h}$ for $4 \mathrm{~h}, 300 \mathrm{U} / \mathrm{h}$ for the next $4 \mathrm{~h}$, then 150 to $200 \mathrm{U} / \mathrm{h}$ for the duration of treatment to be adjusted according to the anti-Xa plasma activity $(0.5-0.8 \mathrm{U} / \mathrm{mL}$, assay with specific calibration).

In paediatrics, the initial dose of danaparoid for a thrombosis is $30 \mathrm{U} / \mathrm{kg}$ (IV bolus) followed by a maintenance dose of 1.2 to $2.0 \mathrm{U} \mathrm{kg} / \mathrm{h}$.

The IV route is preferable, but if the subcutaneous route is preferred with curative doses, the maintenance dose of danaparoid varies according to weight: $1500 \mathrm{U}$ SC 2 times/day if weight $\leq 55 \mathrm{~kg} ; 2000 \mathrm{U}$ SC 2 times/day if $55<$ weight $\leq 90 \mathrm{~kg} ; 1750 \mathrm{U} \mathrm{SC}$ 3 times/day if weight $>90 \mathrm{~kg}$. 
Importantly, the analysis of 294 patients treated with danaparoid in the acute phase of HIT concluded that prophylactic doses are less effective than higher doses administered by continuous IV [55].

Danaparoid can be prescribed in preventive doses in a patient with a previous history of HIT at the following doses: $750 \mathrm{U} \mathrm{SC}$ 2 times/day if the weight $\leq 90 \mathrm{~kg} ; 1250 \mathrm{U}$ SC 2 times/day if the weight $>90 \mathrm{~kg}$.

The summary of product characteristics (SPC) details the protocols adapted to different clinical situations (cardiac catheterisation, coronary angioplasty, arterial embolectomy, peripheral vascular bypass, cardiopulmonary surgery, periodic haemodialysis, daily dialysis, continuous haemofiltration), some of which are discussed in question 11.

3. Monitoring of treatment is necessary in the majority of cases, especially in cases of bleeding risk or renal failure, since danaparoid is mainly eliminated by the kidney. It is also recommended in cases of cachexia and in patients with a weight $>90 \mathrm{~kg}$. It is ensured by measuring the anti-Xa activity, with an adapted dosage method calibrated with specific calibrations. According to the SPC, the anti-Xa activity should be maintained between 0.5 and $0.8 \mathrm{U} / \mathrm{mL}$ for the treatment of acute HIT [3].

A risk of cross-reactivity in vitro of danaparoid with antibodies present in HIT patients exists in 5 to $10 \%$ of cases, but the clinical consequences that may result are rare [57]. Danaparoid therapy can therefore be initiated without waiting for the results of an in vitro cross-reactivity test, which is not mandatory, but platelet counts should be monitored daily until normalised and then twice weekly for the first two weeks of treatment [58]. In the latter case (thrombosis or extension), a control of the anti-Xa activity allows to verify that it is not below $0.5 \mathrm{U} / \mathrm{mL}$.

4. In case of overdose, transient discontinuation of danaparoid is proposed in combination with monitoring of specific anti-Xa activity. In cases of severe bleeding, the use of protamine is not proposed by the danaparoid SPC, although it partially neutralises its anticoagulant activity. Plasmapheresis may be considered in the event of uncontrollable bleeding.

5. The danaparoid sodium-VKA switch is only initiated when the thromboembolic risk is well controlled (usually after 5 to 7 days of treatment), and when the platelets are above $150 \mathrm{G} / \mathrm{L}$. It is recommended to stop danaparoid only when the INR is in the therapeutic window (between 2 and 3 ) for two consecutive days and after a minimum duration of 72 hours of VKA treatment.

\section{Argatroban}

1. Argatroban (Arganova ${ }^{\circledR}$ in France) is a synthetic anticoagulant, which specifically and directly inhibits thrombin, whether free or thrombus-related. It has a short onset of action and a short elimination half-life of less than one hour ( $52 \pm 16 \mathrm{~min})$. In continuous IV infusion, plasma levels reach steady state within 1 to 3 hours (faster if bolus injection).

The efficacy and safety of argatroban in HIT were initially evaluated in two prospective multicentre studies (ARG-911 and ARG-915) involving 882 patients with HIT with or without thrombosis, and compared to historical controls [59,60], and more recently in a French study [61].

The metabolism of argatroban is mainly hepatic. Argatroban is therefore contraindicated in cases of severe liver failure (ChildPugh score C). In patients with moderate hepatic insufficiency (Child-Pugh B score), its clearance can be reduced by a factor of 4 and its half-life multiplied by 3 [62], necessitating a much lower initial dose.

Argatroban is not eliminated by the kidney unlike sodium danaparoid and is therefore preferred in cases of renal failure.

Argatroban contains ethanol. A $70 \mathrm{~kg}$ patient in whom the maximum recommended dose ( 10 micrograms $/ \mathrm{kg} / \mathrm{min}$ ) is administered therefore receives a dose of approximately $4 \mathrm{~g}$ ethanol per day.

2. In acute HIT with or without thrombosis, the initial dosage recommended in the SPC is most often too high $(2 \mu \mathrm{g} / \mathrm{kg} / \mathrm{min})$ and associated with marked prolongation of aPTT and bleeding complications [61]. In patients with impaired liver function, such as after cardiac surgery and in intensive care, the initial dose should be significantly reduced and most often close or equal to $0.5 \mu \mathrm{g} / \mathrm{kg} / \mathrm{min}$. The dosage may be adjusted in patients with multivisceral failure according to APACHE II, SOFA or SAPS [63] severity scores (Table 2) [64]. In obese patients, the initial dose is calculated on the actual weight [65].

3. Argatroban prolongs routine coagulation tests such as the prothrombin time (PT) (and therefore increases INR) and aPTT. The latter can be used as a first-line treatment-monitoring assay [57], but it must be measured before treatment is started to check its "normality". A stable anticoagulant effect is usually achieved only 1 to 3 hours later. The first check should therefore be performed 2 to 3 hours after the start of the infusion. The recommended target value is 1.5 to 3 times the initial value, but not more than 100 seconds, and aPTT should be measured at least once a day; it has the advantage of being available in all laboratories. However, prolonged aPTT before treatment (common in intensive care, after cardiac surgery or in cases of liver failure) sometimes makes it impossible to use this assay for monitoring argatroban. In addition, the effect of argatroban on aPTT depends on the reagent and coagulometer used, and a plateau effect is observed at the upper end of the therapeutic range. Therefore, aPTT is not ideal for the follow-up of a thrombin inhibitor [66] in an unstable clinical context such as HIT, and a target value well below $100 \mathrm{~s}$ must be

Table 2

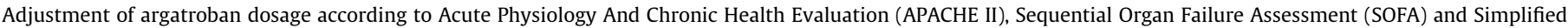
Acute Physiology Score (SAPS) scores. According to Alatri et al. [55].

\begin{tabular}{|c|c|c|c|c|c|}
\hline Score APACHE II & Argatroban $(\mu \mathrm{g} / \mathrm{kg} / \mathrm{min})$ & Score SOFA & Argatroban ( $\mu \mathrm{g} / \mathrm{kg} / \mathrm{min})$ & SAPS & Argatroban $(\mu \mathrm{g} / \mathrm{kg} / \mathrm{min})$ \\
\hline 15 & 1.25 & 10 & 1.28 & 30 & 1.16 \\
\hline 16 & 1.19 & 11 & 1.19 & 32 & 1.10 \\
\hline 17 & 1.13 & 12 & 1.10 & 34 & 1.04 \\
\hline 18 & 1.07 & 13 & 1.01 & 36 & 0.98 \\
\hline 19 & 1.01 & 14 & 0.92 & 38 & 0.92 \\
\hline 20 & 0.95 & 15 & 0.83 & 40 & 0.86 \\
\hline 21 & 0.89 & 16 & 0.74 & 42 & 0.82 \\
\hline 23 & 0.77 & 17 & 0.65 & 44 & 0.74 \\
\hline 25 & 0.65 & 18 & 0.56 & 46 & 0.68 \\
\hline 27 & 0.53 & 19 & 0.47 & 50 & 0.56 \\
\hline 29 & 0.41 & 20 & 0.38 & 55 & 0.41 \\
\hline 32 & 0.23 & 21 & 0.29 & 60 & 0.26 \\
\hline
\end{tabular}


maintained to reduce the risk of bleeding. However, the level of anticoagulation may not be optimal in some cases with pretherapeutic prolongation of aPTT [67].

Other more specific tests with a linear dose-response relationship are available [61]: ecarin clotting time (ECT) and diluted thrombin time (TTd), which both allow the accurate measurement of circulating argatroban levels, with an ideal target value between 0.25 and $1.5 \mu \mathrm{g} / \mathrm{mL}$ [61]. A prescription and monitoring algorithm using aPTT and TTd, potentially useful in clinical practice, was proposed by Rozec et al. in 2014 [64] (Fig. 2).

4. The argatroban-AVK switch is delicate because this antithrombin molecule prolongs the prothrombin time. After the introduction of VKA (coumadin), argatroban should only be stopped when INR value is at least equal to 4 according to the algorithm below (Fig. 3).

\section{Bivalirudin}

Bivalirudin, a synthetic molecule, is a direct thrombin inhibitor [68]. It also prolongs the prothrombin time and its elimination half-life is short, about $25 \mathrm{~min}$ if renal function is normal. Its elimination is mainly enzymatic (80\%) and renal (20\%).

Therapeutic indications include percutaneous coronary intervention and cardiac surgery in patients with heparin-induced thrombocytopenia or high risk of bleeding.

Bivalirudin is the most studied drug in patients with HIT and requiring cardiac surgery or a transluminal angioplasty (see questions \#10 and \#11). Bivalirudin is currently no longer available in France. However, generics may be prescribed in other European countries.

Bivalirudin is administered exclusively intravenously, has no antidote, and is partially haemodialysable (25\%).

\section{Fondaparinux}

Fondaparinux (Arixtra ${ }^{\circledR}$ in France), is a synthetic pentasaccharide specifically inhibiting factor $\mathrm{Xa}$, and has been used for many years in the treatment of HIT, although it was not licensed in this indication, and few cases have been published without any controlled studies.

In 2012, the British guidelines suggested that fondaparinux could be used to treat HIT but only with curative doses [3], taking into account the patient weight ( $5 \mathrm{mg}$ if $<50 \mathrm{~kg}, 7.5 \mathrm{mg}$ if $50-$ $100 \mathrm{~kg}$, and $10 \mathrm{mg}$ if $>100 \mathrm{~kg}$ ), age and kidney function. Since then, other data have supported the use of fondaparinux. A retrospective study compared 133 patients treated with fondaparinux with matched control patients using a propensity score. The efficacy and safety of fondaparinux was considered comparable to that of argatroban or danaparoid administered to patients in the control group [69]. Analysis of a German registry of 195 HIT patients also showed that nearly half of them $(n=83,43.1 \%)$ were treated with fondaparinux despite not licensed in this indication, without complication or death, while $11.7 \%$ of cases treated with an approved anticoagulant (sodium danaparoid, and argatroban in particular) had complications (thrombosis, skin necrosis, amputations) with an intra-hospital mortality of $14.4 \%$ [70]. These data explain why the ASH Expert Group proposed fondaparinux as an acceptable therapeutic option for the treatment of HIT in 2018 [4], but preferably in a stable patient (Proposal \# 24).

There are also several arguments in favour of using fondaparinux in HIT: it has no cross-reactivity with anti-PF4 antibodies, unlike sodium danaparoid; it is easy to administer (one daily subcutaneous injection), and requires no dosage adjustment or specific bioassay; it has no effect on aPTT, whose prolongation thus shows more reliably an underlying coagulopathy, nor on Quick time and INR, which facilitates a relay by AVK; finally, the cost of treatment with fondaparinux is lower than that of danaparoid or argatroban [71].

Fondaparinux is eliminated exclusively by the kidney and haemorrhages associated with its use in renal failure have been reported, particularly after cardiac surgery [72]. This drug should therefore not be used in cases of severe renal failure and should be avoided if the patient's clinical condition is unstable.

\section{Direct oral anticoagulants}

Direct oral anticoagulants (DOAs) currently include a thrombin inhibitor (dabigatran or Pradaxa ${ }^{\mathbb{R}}$ ) and several Xa inhibitors, rivaroxaban $\left(\right.$ Xarelto $^{\mathbb{}}{ }^{\text {}}$ ), apixaban $\left(\right.$ Eliquis ${ }^{\circledR}$ ) and edoxaban (Lixiana ${ }^{\circledR}$ ) more recently approved in France. DOACs are widely prescribed in atrial fibrillation but also in venous thromboembolic disease, particularly Xabans. These reasons explain why they were logically proposed to treat HIT.

In 2012, Krauel et al. demonstrated that both dabigatran and rivaroxaban had no effect on the interactions between PF4 or PF4/ heparin complexes and platelets [73]. Then, several articles reported isolated cases or small series of patients with HIT, treated with dabigatran, rivaroxaban and more rarely apixaban. In 2015, Sharifi et al. reported 22 patients initially treated with low doses of argatroban and then with dabigatran $(n=6)$, rivaroxaban $(n=11)$ or apixaban $(n=5)$. Five patients presented a new thrombotic episode, suggesting a very relative efficacy of DOACs, but this retrospective study was questionable because the diagnosis of HIT was not always very well documented (no bioassay in 2 cases) and the initial treatment with argatroban was not optimal [74].

In 2016, Linkins et al. presented the results of the only prospective study that evaluated a DOAC in HIT [75]. This drug was rivaroxaban, but the strict inclusion criteria allowed only 22 patients to be included, with only 12 HIT cases confirmed by the SRA. All patients were treated with rivaroxaban $15 \mathrm{mg}$ bid, continued in case of confirmed HIT until thrombocytopenia was corrected or until D21 in case of thrombosis. Then, the dosage was reduced to $20 \mathrm{mg}$ per day $(2 \times 10)$ until D30. Of the 12 cases of HIT, 6 had thrombosis and/or adrenal haemorrhagic necrosis. It should also be noted that 6 patients had received fondaparinux before inclusion for 2 or 3 days. The evolution of platelet count was favourable in 9 of the 10 cases with initial thrombocytopenia after a delay varying between 3 and 29 days. The $10^{\text {th }}$ patient died on D21 of metastatic gastric cancer. Only one patient had a thrombotic recurrence with an extension of venous thrombosis of the upper limbs. Another study involving 9 patients with HIT complicated by thrombosis also reported an efficacy of rivaroxaban since in all cases the clinical and biological evolution was favourable [76].

In 2017, Warkentin et al. reviewed the literature according to whether patients were treated by a DOAC in the acute or subacute phase of HIT as $1^{\text {st }}$ or $2^{\text {nd }}$ line after at least one dose of fondaparinux, danaparoid sodium, argatroban or bivalirudin. They concluded that DOACs are a possible option for the treatment of HIT. Based on this analysis and data from an additional study [77] (Table 3), ASH experts [4] proposed rivaroxaban to treat patients who do not have life-threatening and/or functional thrombosis, while injectable anticoagulants were preferred in more severe cases.

Apixaban, which is also an anti-Xa with a good benefit/risk ratio, is probably also an option in the same way as rivaroxaban.

Our proposal is therefore that DOACs may in some cases be an option for the treatment of HIT (proposals \#15 and \#24), but their prescription should not lead to neglecting the necessary approach to the diagnosis of HIT, and in particular the prescription of confirmatory biological tests. 


\section{Argatroban prescription algorithm for HIT}

Argatroban is contraindicated in cases of severe liver failure (Child-Pugh C) and fructose intolerance
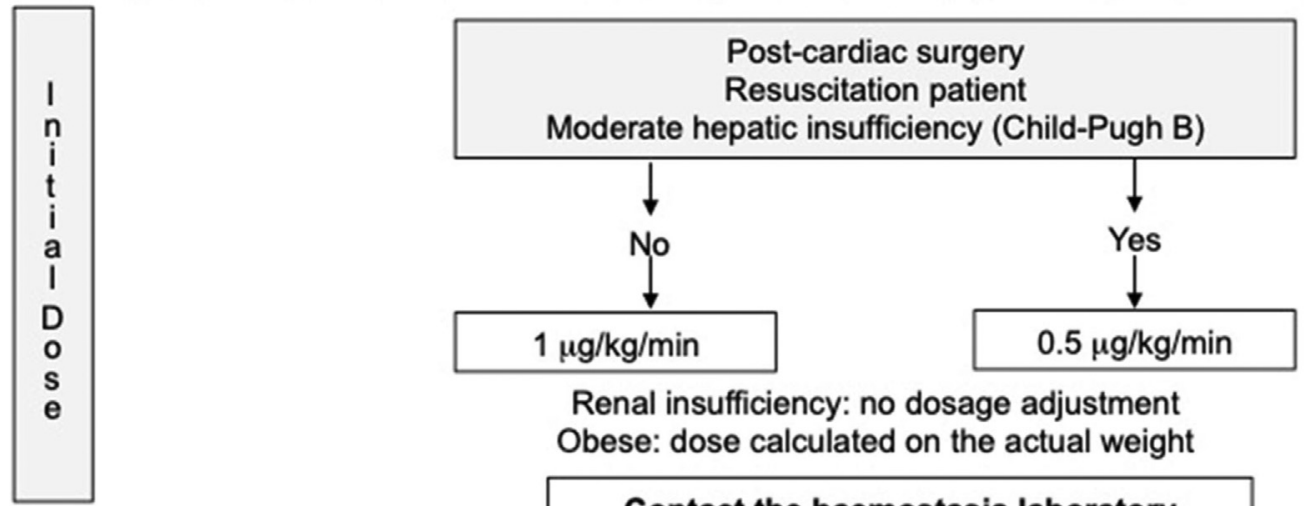

Renal insufficiency: no dosage adjustment Obese: dose calculated on the actual weight

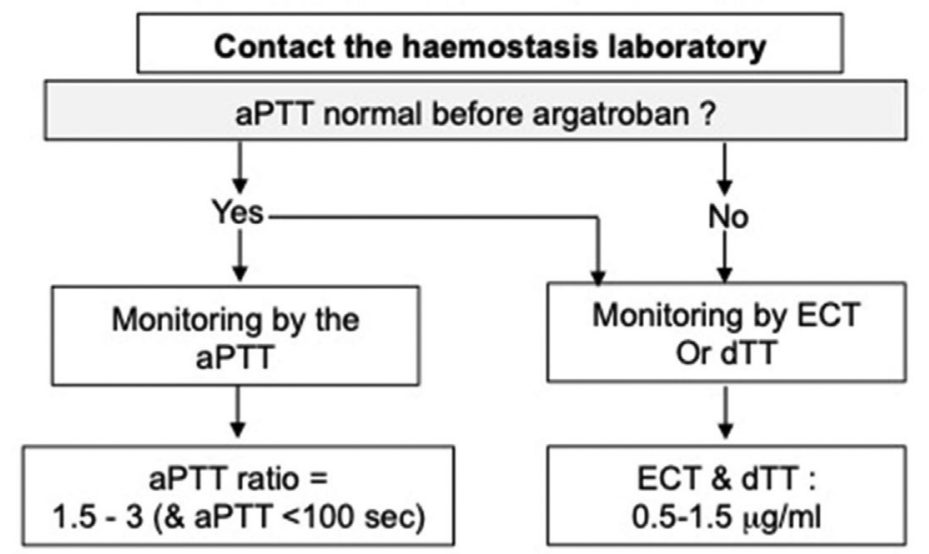

ECT: Ecarin clotting time;

dTTd : diluted thrombin time; aPTT: activated partial thromboplastin time;

\begin{tabular}{|c|c|c|c|c|}
\hline \multirow[b]{2}{*}{ Monitoring } & \multicolumn{2}{|c|}{$\begin{array}{l}\text { Standard treatment } \\
\text { Start of infusion at } 2 \mu \mathrm{g} / \mathrm{kg} / \mathrm{min}\end{array}$} & \multicolumn{2}{|c|}{$\begin{array}{l}\text { Treatment at low doses } \\
\text { Start of infusion at } 0,5 \mu \mathrm{g} / \mathrm{kg} / \mathrm{min}\end{array}$} \\
\hline & Dosage changes & Next assay & Dosage changes & Next assay \\
\hline Under-dosing & $\begin{array}{l}\text { Increase of } 0,5 \mu \mathrm{g} / \\
\mathrm{kg} / \mathrm{min}\end{array}$ & $2 \mathrm{~h}$ later & $\begin{array}{l}\text { Increase of } 0,1 \mu \mathrm{g} / \\
\mathrm{kg} / \mathrm{min}\end{array}$ & $4 \mathrm{~h}$ later \\
\hline $\begin{array}{l}\text { Therapeutic } \\
\text { range }\end{array}$ & No change & $\begin{array}{c}2 \mathrm{~h} \text { later, then } \\
\text { once a day } \\
\text { after } 2 \text { assays } \\
\text { within the } \\
\text { therapeutic } \\
\text { range }\end{array}$ & No change & $\begin{array}{c}4 \mathrm{~h} \text { later, then } \\
\text { once a day after } \\
2 \text { assays within } \\
\text { the therapeutic } \\
\text { range }\end{array}$ \\
\hline Overdosage & $\begin{array}{l}\text { Stop the infusion } \\
\text { until the monitoring } \\
\text { test is in the } \\
\text { therapeutic range } \\
\text { and resume at a } \\
\text { rate half the } \\
\text { previous rate }\end{array}$ & $2 \mathrm{~h}$ later & $\begin{array}{l}\text { Stop the infusion } \\
\text { until the monitoring } \\
\text { test is in the } \\
\text { therapeutic range } \\
\text { and resume at a } \\
\text { rate half the } \\
\text { previous rate }\end{array}$ & $4 \mathrm{~h}$ later \\
\hline
\end{tabular}

Fig. 2. Algorithm for prescribing and monitoring argatroban in heparin-induced thrombocytopenia (HIT). 


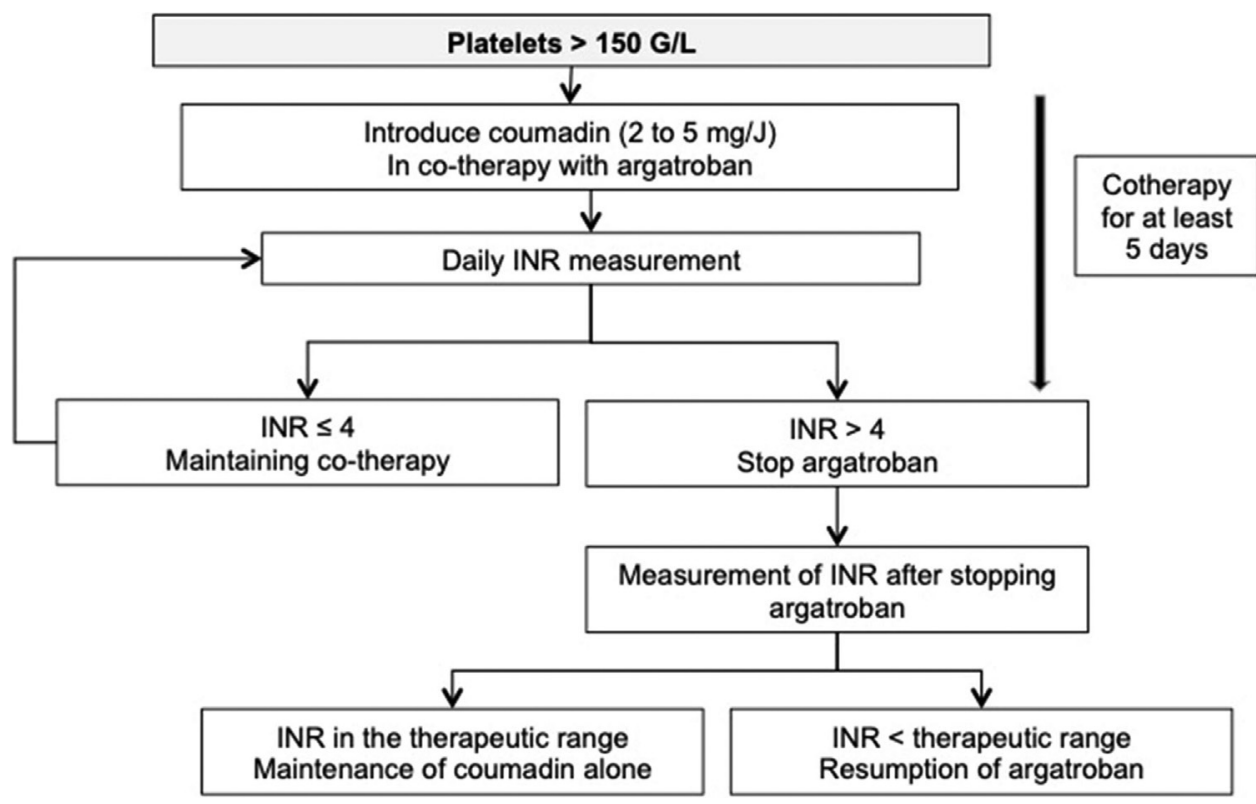

Fig. 3. Modalities of the argatroban-vitamin K antagonist (VKA) switch according to Rozec et al. [64].

Table 3

Main results obtained with anti-Xa DOACs in the treatment of HIT; according to Warkentin et al. [77], Davis and Davis [112] and Cuker et al. [4].

\begin{tabular}{|c|c|c|c|c|c|}
\hline DOAC & $n$ & HIT with thrombosis & DOAC as a $1^{\text {st }}$ treatment & Thrombosis & Major bleeds \\
\hline Rivaroxaban & 49 & $31(63 \%)$ & $25(51 \%)$ & $1 / 49$ & $0 / 49$ \\
\hline Apixaban & 21 & $8(38 \%)$ & $7(33 \%)$ & $0 / 21$ & $0 / 21$ \\
\hline Dabigatran & 11 & $6(55 \%)$ & $3(27 \%)$ & $1 / 11$ & $0 / 11$ \\
\hline
\end{tabular}

HIT: heparin-induced thrombocytopenia.

Rivaroxaban with curative doses $(15 \mathrm{mg} \times 2$ /day until D21 or complete and stable correction of thrombocytopenia), then $20 \mathrm{mg} /$ day for at least one month, whether or not there are thrombotic complications, is preferred as the most evaluated DOAC in this situation.

Vitamin $K$ antagonists (VKA)

VKA should never be used alone in the acute phase of HIT as they can promote the spread of venous thrombosis, their progression to gangrene or the development of skin necrosis at this stage [7]. VKA are administered only under the cover of effective parenteral anticoagulant therapy (danaparoid sodium or argatroban). Coumadin is preferred and administered as soon as possible, when platelet re-ascension is confirmed (platelets $>150 \mathrm{G} / \mathrm{L}$ ). The danaparoid sodium-coumadin and argatrobancoumadin switches require precautions as described above.

In addition, the British and ASH proposed that VKA should be stopped in patients with acute or subacute HIT previously treated, and vitamin $\mathrm{K}$ injected before starting the non-heparin anticoagulant $[3,4]$.

Practical modalities for the use of non-heparin anticoagulants in the acute phase of HIT

The choice of treatment (argatroban, bivalirudin, danaparoid, anti-Xa DOACs or fondaparinux) will be influenced by several factors, some of which are specific to the usable drugs (availability, biological monitoring modalities, route of administration, $1 / 2$ elimination life, cost) and others are more patient-related (renal and hepatic functions, clinical condition, severity of associated thrombosis, risk of spontaneous bleeding or caused by a procedure). The clinician's experience will also be an element that will guide the choice. The duration of non-heparin anticoagulant therapy is at least 4 weeks in patients with isolated thrombocytopenia, and at least 3 to 6 months in other cases depending on the site and severity of associated thrombosis $[3,4]$.

Question 8: Is there a place for other treatments in a patient with suspected HIT?

Proposal \# 24

It is recommended not to transfuse platelets in the acute phase of HIT in the absence of life-threatening or functional bleeding.

(STRONG AGREEMENT)

Proposal \# 25

It is recommended not to prescribe an oral antiplatelet agent to treat acute HIT.

(STRONG AGREEMENT)

Proposal \# 26

It is proposed not to prescribe IV immunoglobulins as a firstline treatment for the acute phase of HIT.

(STRONG AGREEMENT)

Proposal \# 27

It is proposed not to insert an inferior vena cava filter in the acute phase of HIT.

(STRONG AGREEMENT) 
Rationale

Apart from anticoagulants, other therapeutic approaches can be discussed but their place is very limited in practice.

1. Polyvalent intravenous immunoglobulins have been used in a few cases of HIT [78-80] but their efficacy remains poorly documented. They cannot be recommended for the treatment of acute HIT. However, they have recently been proposed for severe and very rare so-called "autoimmune" HIT [81].

2. Plasmapheresis or plasma exchanges have also been exceptionally used in acute HIT and mainly in the context of urgent cardiovascular surgery [82] (see question 10). However, their relative benefit compared to powerful antiplatelet drugs such as ilomedine or tirofiban has not been evaluated.

3. Antiplatelet agents (APA) cannot be used alone to treat HIT.

The value of combining APA with a non-heparin anticoagulant may be discussed in some cases of HIT with severe arterial thrombotic complications. However, this combination increases the risk of bleeding and its effectiveness has not been validated.

In patients receiving long-term APA therapy for atheromatous disease (e.g. coronary artery disease, lower limb arteriopathy) with HIT, the decision to continue APA is made taking into account the risk of bleeding and vascular risk.

GPIIb-IIIa receptor antagonists have been used successfully in rare cases of acute coronary occlusion after angioplasty during HIT. Tirofiban (Agrastat ${ }^{\mathbb{R}}$ ) is an option to be discussed only in case of cardiac surgery (see question 10). Iloprost (Ilomédine ${ }^{\circledR}$ ), a prostacyclin analogue, induces risks of severe hypotension, and is rarely used today (see question 10). However, it remains available as a therapeutic option by ASH in the event of emergency cardiac surgery [4].

4. LMWH are contraindicated in UFH-HIT patients because they often result in in vivo platelet activation associated with a risk of persistent thrombocytopenia with thrombosis.

5. Thrombolytics can exceptionally be discussed for the management of serious thrombotic complications sometimes observed during HIT.

6 . VKA should never be used alone as they expose the patient to an increased risk of thrombosis and skin necrosis (see question 7).

7. Platelet transfusion is not recommended because it can promote the onset of thrombosis [83] or the process of consumption, and is often ineffective. Platelet transfusions are therefore only considered in cases of severe bleeding.

8 . The insertion of a vena cava filter should only be discussed in cases of severe pulmonary embolism with a high risk of bleeding and transient contraindication of anticoagulants, as this procedure is associated with a risk of acute thrombotic obliteration.

9. Surgical thrombectomy is performed exceptionally when ischemia threatens the functional prognosis of the $\operatorname{limb}(\mathrm{s})$ and/or the vital prognosis.

\section{Question 9: What treatment should be offered for HIT in surgical settings outside cardiac surgery?}

\section{Proposal \# 28}

In a patient with acute HIT (less than 1 month), it is proposed to postpone any surgery beyond the first month following the diagnosis of HIT if this does not generate a major vital or functional risk for the patient, and to define the modalities during a multidisciplinary consultation.

(STRONG AGREEMENT)

\section{Proposal \# 29}

In case of surgery in a patient treated with an oral anticoagulant and having acute HIT (less than 1 month), it is proposed to stop this anticoagulant and discuss a preoperative bridging with argatroban or bivalirudin, with stopping the infusion 4 hours before the procedure for argatroban and 2 hours for bivalirudin.

(STRONG AGREEMENT)

\section{Proposal \# 30}

In postoperative care, if prolonged anticoagulation is needed and the risk of bleeding is controlled, it is proposed to treat the patient preferentially with fondaparinux or an oral anticoagulant (VKA or DOAC), taking into account contraindications and precautions of use.

(STRONG AGREEMENT)

\section{Rationale}

In all cases, the diagnosis of HIT (4T score, biological results, thrombotic complication) should be confirmed and the referring haemostasis team in the region should be contacted. In case of acute HIT, it is preferable to postpone the surgical procedure for at least 1 month, especially if the patient has had HIT with thrombosis.

In case of procedures usually performed under heparin (vascular surgery, coronary angioplasty, endovascular procedure), it is recommended to look for anti-PF4/heparin antibodies (ELISA test). If they are undetectable, short-term treatment with unfractionated heparin is possible during the procedure.

\section{Preoperatively}

1. If the patient is treated for recent HIT with a parenteral anticoagulant (danaparoid, argatroban, bivalirudin, or fondaparinux), the surgical procedure should be deferred if possible. Otherwise, the discontinuation of the anticoagulant will be decided on a case-by-case basis, taking into account its elimination half-life and the haemorrhagic risk associated with the surgical procedure. Given the long half-life of danaparoid and fondaparinux, a relay with argatroban or bivalirudin may be proposed if the risk is considered too high. Biological assays, if available, are helpful in the management (Table 4).

2 . If the patient is treated with an oral anticoagulant (VKA or DOAC), discontinuation of treatment is managed according to usual recommendations $[83,84]$.

Preoperative relaying of the oral anticoagulant with a nonheparinic injectable anticoagulant will only be discussed in situations of high thrombotic risk (HIT $<1$ month, thromboembolic event $<3$ months or recurrent, mechanical heart valve, atrial fibrillation with embolic history). In this case, the proposed anticoagulant is either argatroban or bivalirudin due to their short half-life [63].

\section{Local and regional anaesthesia}

The performance of neuraxial procedures is contraindicated under anticoagulant. These procedures include diagnostic or therapeutic lumbar punctures, spinal anaesthesia and therapeutic spinal injections, whether or not guided by radio, as well as epidurals with or without catheters.

A neural gesture can be performed after the following stopping times: for argatroban: 8 hours after stopping the infusion and if a plasma dose confirms a level $<0.1 \mu \mathrm{g} / \mathrm{mL}$ [62]; for bivalirudin: 
Table 4

Management of anticoagulants used in HIT before surgery.

\begin{tabular}{|c|c|c|}
\hline Anticoagulant & Half-life & Proposed management \\
\hline Fondaparinux & About $17 \mathrm{~h}$ (anti-Xa) & Last injection $>36 \mathrm{~h}$ before surgery \\
\hline Danaparoid & About $24 \mathrm{~h}$ (anti-Xa) and $7 \mathrm{~h}$ (anti-Iia) & Stop infusion or last SC injection $>36 \mathrm{~h}$ before surgery \\
\hline Argatroban & About 50 minutes & Stop infusion $4 \mathrm{~h}$ before surgery \\
\hline Bivalirudin & About $20-30$ minutes & Stop infusion $2 \mathrm{~h}$ before surgery \\
\hline
\end{tabular}

HIT: heparin-induced thrombocytopenia.

8 hours after stopping the infusion; for DOACs, last dose at D-5 or plasma concentration $<30 \mathrm{ng} / \mathrm{mL}$; for danaparoid and fondaparinux, the objective is to obtain levels $<$ detection threshold i.e. $<0.1 \mathrm{U}$ anti-Xa/mL for danaparoid, and $<0.1 \mathrm{mg} / \mathrm{mL}$ for fondaparinux. A stop of more than 48 hours is probably necessary in most cases.

However, in the case of acute HIT ( $<1$ month), the relatively long stopping times of DOACs, danaparoid, and fondaparinux expose the patient to a high thrombotic risk. If they are only justified by a neuraxial procedure, another type of anaesthesia should be considered.

\section{Intraoperatively}

This part only concerns procedures that require anticoagulant treatment during the surgery. If time permits, a search for anti-PF4/ heparin antibodies (ELISA test) is recommended; if the antibodies are no longer detectable, exposure to heparin is possible during the procedure.

If anti-PF4/heparin antibodies are present, it is proposed to discuss the administration of danaparoid, argatroban or bivalirudin according to the available protocols, renal status and liver status of the patient (see question 6).

\section{Postoperatively}

Anticoagulant treatment can be resumed from the 6th postoperative hour, after assessment of the risk of bleeding. The choice of the drug to be prescribed is based on:

- the elimination half-life in case of risk of haemorrhage and/or surgical resumption: 50 minutes for argatroban, 24 hours (antiXa activity) for danaparoid, 17 hours for fondaparinux;

- the experience in the service and availability of biological surveillance tests (measurement of anti-Xa activity - danaparoid range, argatroban assay rather than aPTT, with the help of a haemostasis specialist);

- if renal failure: no accumulation with argatroban, close followup of anticoagulation with danaparoid (anti-Xa activity danaparoid range);

- if liver failure: calculation of the Child-Pugh score, with in the case of a value $>6$, an elimination half-life of argatroban that increases from 50 to 152 minutes [62].

In case of HIT $<1$ month, danaparoid should preferably be prescribed by IV route and with curative doses, adjusting the dosage on anti-Xa activity maintained between 0.5 and $0.8 \mathrm{U} / \mathrm{mL}$ (danaparoid range) (see question 7).

Argatroban IV will be prescribed at a low initial dose $(0.5 \mu \mathrm{g} / \mathrm{kg} /$ minute), then adjusted to aPTT or better plasma concentration, with a target value between 0.5 and $1.5 \mu \mathrm{g} / \mathrm{mL}$ [61].

If prolonged anticoagulant therapy is required, and considering that danaparoid and argatroban are subject to hospital prescription, it is proposed to prescribe fondaparinux or preferably oral anticoagulant, AVK or AOD (rivaroxaban) in the event of long-term anticoagulant therapy.
Question 10: Which treatment should be offered for cardiac surgery with and without cardiopulmonary bypass in the case of HIT?

Proposal \# 31

Before any cardiac surgery in a patient with a documented history of HIT, it is proposed to systematically perform an ELISA for anti-PF4 antibodies.

(STRONG AGREEMENT)

\section{Proposal \# 32}

Before any cardiac surgery with cardiopulmonary bypass in a patient with acute or subacute HIT ( $<3$ months), it is proposed to define the perioperative anticoagulation protocol in a multidisciplinary consultation.

(STRONG AGREEMENT)

Proposal \# 33

In a patient with acute or subacute HIT with a significant titre of anti-PF4 antibody (ELISA with DO $>1$ ) and requiring cardiac surgery with cardiopulmonary bypass, possible strategies for intraoperative anticoagulation are to combine an IV antiplatelet agent (tirofiban or cangrelor) and UFH, or to administer a direct antithrombin agent (bivalirudin or argatroban) with close biological monitoring.

In case of urgent surgery, it is proposed to favour an association antiplatelet IV + UFH.

(STRONG AGREEMENT)

Rationale

Unscheduled cardiac surgery in a patient with acute HIT is one of the most difficult situations to manage, as unfractionated heparin remains the anticoagulant of choice for extracorporeal circulation, and as the available alternatives do not offer the same benefit/risk ratio.

In any case, it is appropriate (Fig. 4):

- to have confirmed the diagnosis of HIT (4T score, biological results, thrombotic complication);

- to contact the leading haemostasis team in the region;

- to postpone the procedure if possible for more than 3 months after HIT, or at least 1 month after a possible thrombotic complication;

- to perform an ELISA test for anti-PF4/heparin antibodies: if it is negative, the procedure is identical to that to be followed for an old HIT (see question 11) and short-term re-exposure to heparin is possible, particularly for cardiopulmonary bypass.

\section{If HIT is acute or subacute ( $<3$ months)}

In this situation, the patient often has a residual titre of anti-PF4 antibodies, especially if one is very close to HIT (within a month) 
Cardiac surgery with cardiopulmonary bypass (CPB)

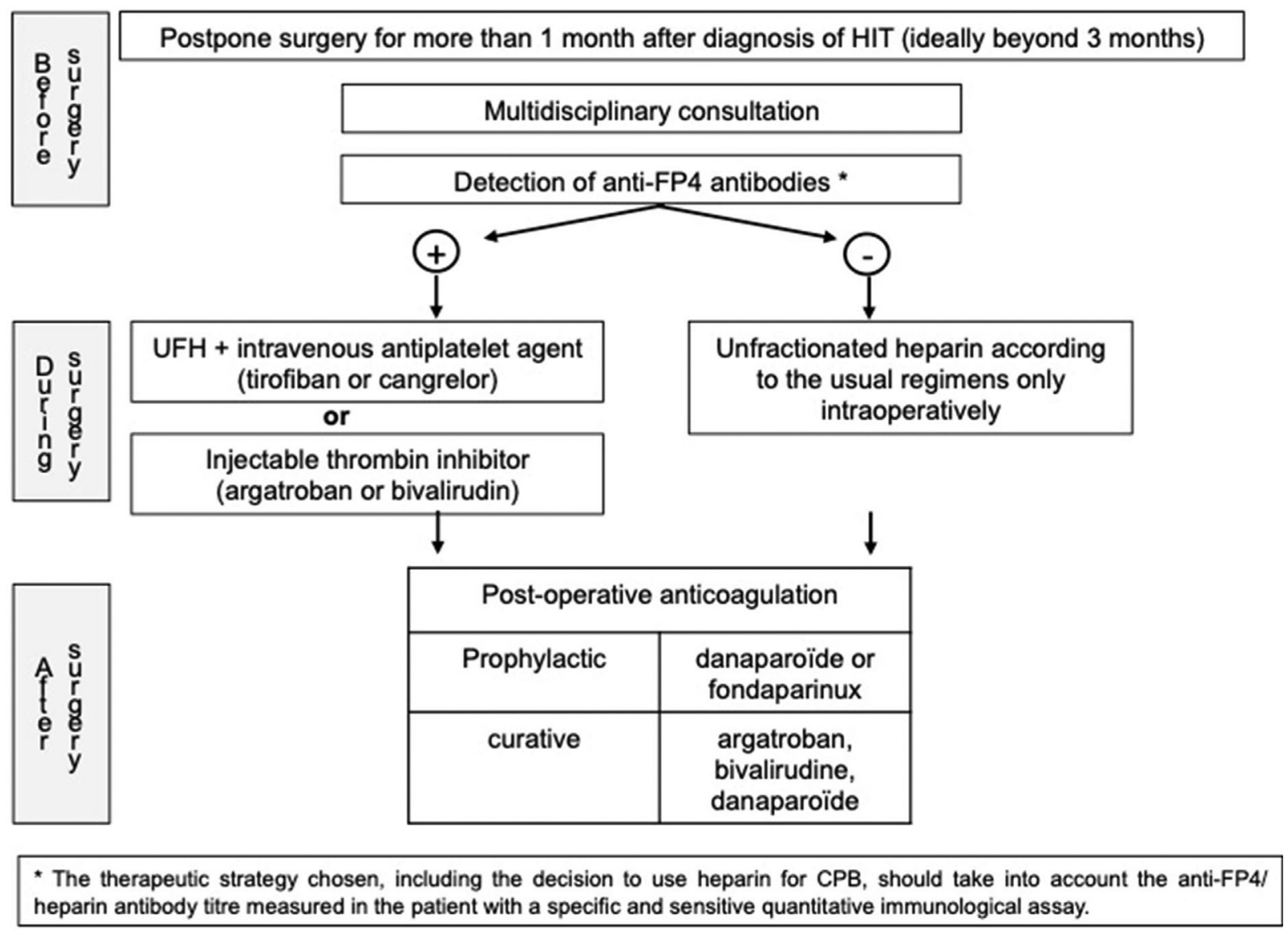

Fig. 4. Therapeutic strategies for cardiac surgery in heparin-induced thrombocytopenia (HIT) patients.

and re-exposure to unfractionated heparin without particular caution is therefore a priori contraindicated, as it exposes the patient to a recurrence of thrombocytopenia or even thrombosis.

However, this position is discussed because the ASH recommendations distinguish two types of patients with subacute HIT (with normal platelet count) and residual anti-PF4 antibodies. The first are those for whom a platelet activation test (mainly SRA) is positive. In these cases, HIT is considered to be subacute type A and the administration of heparin for cardiac surgery should be avoided. The second group is patients with a negative SRA, and considered to have subacute HIT type B, and for ASH experts heparin use during cardiac surgery is possible [4].

This distinction and the resulting position are, in our opinion, highly questionable because SRA may not be sensitive enough to formally eliminate the presence of potentially pathogenic antibodies in the patient's plasma during cardiac surgery. This is all the more true since it has been shown that the addition of exogenous PF4 allows SRA to be positive [85], and cardiopulmonary bypass induces a significant and rapid increase in plasma PF4 concentration in operated patients.

The anti-PF4 antibody titre estimated in ELISA is also important to define because, when elevated with an OD greater than 1.5 , the clinical risk is likely to be higher after re-exposure to heparin, compared to a patient with a lower antibody concentration (with an $\mathrm{OD}<1$ ).

It is therefore essential that in all cases, the anticoagulation protocol be defined within the framework of multidisciplinary consultation (anaesthetist, surgeon, haemostasis specialist), taking into account the team's experience, the available drugs and the biological tests performed $[86,87]$.

In the preoperative period

The proposals for anticoagulant treatment are identical to those for conventional surgery (see question 9 ).

Plasma exchanges that are intended to minimise the level of circulating antibodies are also possible. They can be performed preoperatively or in the operating theatre with a volume of FFP equal to the theoretical plasma volume $\times 1.3$ and before heparin is administered during the procedure. However, data on this strategy are limited $[82,88,89]$. In addition, the objective to be achieved is poorly defined (negative ELISA? negativation of the SRA?) and in most cases, a significant titre of anti-PF4/heparin antibodies persists in ELISA [89].

\section{Intraoperatively}

Two strategies are possible.

The first combines an intravenous antiplatelet agent and unfractionated heparin

This strategy consists of inhibiting platelet aggregation before administering heparin so that IgG-PF4-heparin complexes cannot induce platelet activation or thrombus formation. Heparin is injected as a bolus, monitored with ACT and neutralised by protamine on the end of surgery as usual. This strategy is limited to 
the cardiac surgery operating room, and any other administration of heparin is strictly contraindicated (heparin lock, catheter flush, routine administration).

Two antiplatelet agents can be used: tirofiban, a GPIIbIIIa platelet receptor inhibitor, is administered as an IV bolus $(10 \mu \mathrm{g} /$ $\mathrm{kg}$ ) followed 15 minutes later by the usual injection of heparin, then a continuous IV infusion $(0.15 \mu \mathrm{g} / \mathrm{kg}$ per minute) is initiated, stopped 1 hour before the end of cardiopulmonary bypass, at the time of aortic declamping [90]. However, its prolonged effect exposes the patient to bleeding at the end of the bypass and in immediate postoperative care because correction of platelet function is obtained only 8 hours after stopping the tirofiban infusion. Renal failure extends this time. In addition, early discontinuation of the infusion is a problem in the event of a resumption of cardiac surgery.

Cangrelor, a P2Y12 platelet receptor inhibitor, has the advantage of an immediate effect, obtained in $2 \mathrm{~min}$ and a short half-life of 3 to $6 \mathrm{~min}$. The platelet inhibition it induces is stable during infusion and not affected by renal or hepatic failure or blood stagnation. However, its use in the case of HIT is still poorly documented. The proposed protocol is as follows: intravenous bolus of $30 \mu \mathrm{g} / \mathrm{kg} 10$ minutes before heparin administration according to the usual regimen, immediately followed by an IV infusion of $4 \mu \mathrm{g} / \mathrm{kg} / \mathrm{min}$, interrupted $5 \mathrm{~min}$ before the CPB is stopped $[91,92]$. Monitoring of platelet function has been proposed using VerifyNow ${ }^{\circledR}$, but target values are not defined.

Iloprost (Ilomédine ${ }^{\mathbb{R}}$ ) is still sometimes used. This prostacyclin analogue has a half-life of 15 to $30 \mathrm{~min}$. It can be administered as an infusion of 6 to $12 \mathrm{ng} / \mathrm{kg} / \mathrm{min}$, stopped 20 minutes before protamine. However, it does expose to episodes of severe low blood pressure.

\section{The second uses a thrombin inhibitor anticoagulant: bivalirudin or} argatroban

Argatroban is an option but experience is limited and bleeding and/or thrombotic complications (presence of clots in the cardiotomy reservoir or pericardium) have been reported at the time of the bypass procedure. It was not proposed in the 2012 ACCP recommendations that favoured bivalirudin, and it remains poorly or not recommended by some experts in this context $[4,87]$.
Its use involves a bolus of $100 \mu \mathrm{g} / \mathrm{kg}$ followed by a continuous IV infusion at $5 \mu \mathrm{g} / \mathrm{kg} / \mathrm{min}$ with an ACT evaluation $>400$ seconds to start (ECC), then every 15 minutes with a maintenance between 500 and 600 seconds during the procedure. Very prolonged ACTs were observed, complicating the adjustment of the infusion rate [64,93].

Bivalirudin is also a possible option for emergency cardiac surgery in the acute phase of HIT [4,94], although Angiox ${ }^{\mathbb{R}}$ has no longer been marketed in France since the end of 2017, but generics should soon be available.

Bivalirudin is prescribed and monitored as defined in Table 5.

\section{In postoperative care}

Anticoagulant treatment can be resumed from the $6^{\text {th }}$ postoperative hour, after assessment of the risk of bleeding: as a preventive dose with danaparoid or fondaparinux, or with curative doses of argatroban rather than danaparoid, considering its short half-life (50 minutes) starting with an initial dose of $0.5 \mu \mathrm{g} / \mathrm{kg}$ per minute, or defined according to APACHE II, SAPS 2 or SOFA (see question 7) [63]. In cases of severe liver failure (Child-Pugh $C$ score), danaparoid is preferred.

When ECMO is used, the possible options are argatroban and danaparoid, the former being easier to manage given its short half-life. However, patients' organ failures alter the pharmacokinetics of argatroban and require dosage reductions, often below $0.5 \mu \mathrm{g} / \mathrm{kg} / \mathrm{min}$ (see question 7) at the outset of treatment. Frequent biological monitoring is necessary to adapt the doses to the patient's evolution and failures. Diluted thrombin time or ecarin time is preferable to aPTT, which is often already prolonged. Danaparoid, with its long half-life, is difficult to use in this context of high risk of bleeding and invasive procedures.

\section{In the case of surgery with HIT in remission ( $>3$ months)}

Cardiac surgery with or without CPB may be performed under heparin, according to the usual protocol. However, it is recommended to test for anti-PF4/heparin antibodies, as the persistence of pathogenic antibodies for several months or even for a prolonged period has been reported in rare cases.

Table 5

Practical use of bivalirudin in HIT.

\begin{tabular}{|c|c|c|}
\hline & Dosage & Monitoring \\
\hline Medical treatment of HIT (few data) & Start IV infusion at $0.15-0.25 \mathrm{mg} / \mathrm{kg}$ per hour & aPTT target: 1.5 to $2.5 \times$ control time \\
\hline Coronary angioplasty & $\begin{array}{l}\text { IV bolus of } 0.75 \mathrm{mg} / \mathrm{kg} \text { then IV infusion at } 1.75 \mathrm{mg} / \mathrm{kg} \text { per } \\
\text { hour during the procedure and } 4 \text { hours maximum after } \\
\text { the procedure (if creatinine clearance between } 30 \text { and } \\
59 \mathrm{~mL} / \mathrm{min} \text { : start infusion at } 1.4 \mathrm{mg} / \mathrm{kg} \text { per hour) }\end{array}$ & If ACT after IV bolus $<225$ seconds, $2^{\text {nd }}$ bolus of $0.3 \mathrm{mg} / \mathrm{kg}$ \\
\hline \multicolumn{3}{|l|}{ Cardiac surgery } \\
\hline Without CPB & $\begin{array}{l}\text { IV bolus of } 0.75 \mathrm{mg} / \mathrm{kg} \text { and IV infusion at } 1.75 \mathrm{mg} / \mathrm{kg} \text { per } \\
\text { hour during the procedure }\end{array}$ & $\begin{array}{l}\text { If } \mathrm{ACT}<300 \text { seconds, increase infusion rate by } 0.25 \mathrm{mg} / \mathrm{kg} \text { per } \\
\text { hour }\end{array}$ \\
\hline With CPB & $\begin{array}{l}\text { IV bolus of } 1 \mathrm{mg} / \mathrm{kg}+50 \mathrm{mg} \text { in pump priming fluid then } \\
\text { IV infusion at } 2.5 \mathrm{mg} / \mathrm{kg} \text { per hour during the procedure } \\
\text { Stopping the infusion } 15 \text { minutes before the announced } \\
\text { end of the CPB (if still in CPB } 20 \text { minutes, bolus IV } 0.5 \mathrm{mg} / \\
\mathrm{kg} \text { and restart the IV infusion at } 2.5 \mathrm{mg} / \mathrm{kg} \text { per hour) } \\
\text { Caution should be exercised when considering the } \\
\text { enzymatic degradation of bivalirudin (cleavage by } \\
\text { thrombin): avoid pericardial aspiration, avoid blood } \\
\text { stasis }\end{array}$ & $\begin{array}{l}\text { If } \mathrm{ACT}<2.5 \times \text { basic } \mathrm{ACT} \text {, additional bolus from } 0.1 \text { to } 0.5 \mathrm{mg} / \mathrm{kg} \\
\text { Possible measurement of bivalirudin level in whole blood (expert } \\
\text { opinion) }\end{array}$ \\
\hline
\end{tabular}

HIT: heparin-induced thrombocytopenia. 
Question 11: Which treatments are available for HIT in medicine, obstetrics or paediatrics?

\section{Proposal \# 34}

In the case of acute HIT, it is proposed to treat patients requiring transluminal angioplasty for acute coronary syndrome, preferably with bivalirudin or an analogue, or failing that with argatroban.

(STRONG AGREEMENT)

Proposal \# 35

In the case of HIT, it is proposed for renal replacement therapy to use citrate or argatroban as the preferred treatment for circuit anticoagulation.

(STRONG AGREEMENT)

\section{Proposal \# 36}

In case of HIT during pregnancy, it is proposed to treat patients preferentially with danaparoid or if this drug is not available, with fondaparinux.

(STRONG AGREEMENT)

Proposal \# 37

It is proposed that the procedures for monitoring platelet counts in children treated with heparin should be the same as those recommended for adults.

(STRONG AGREEMENT)

\section{Proposal \# 38}

It is proposed that treatment of HIT in children should be provided by sodium danaparoid or argatroban, with rigorous dose adjustment based on weight and bioassay results.

(STRONG AGREEMENT)

\section{Rationale}

The general principles of HIT treatment in medical settings do not differ from those applied to surgical patients. Nevertheless, we will address several specific situations: acute coronary syndrome, renal failure, pregnancy and childhood.

\section{HIT and acute coronary syndrome}

No randomised studies have compared non-heparin anticoagulants in patients with HIT and acute coronary syndrome (ACS) requiring emergency transluminal angioplasty. Bivalirudin [95] and argatroban [96,97] were successfully administered in small groups of patients. A study conducted in 19,772 patients without HIT showed that bivalirudin induces a lower risk of bleeding [98]. The experience of danaparoid sodium in this situation (ACS and HIT) is patchy [57] and the longer elimination half-life of this drug does not encourage its selection as a priority.

The recommended regimen for bivalirudin is a bolus of $0.75 \mathrm{mg} / \mathrm{kg}$ followed by an intravenous infusion of $1.75 \mathrm{mg} / \mathrm{kg} /$ hour. For argatroban, a bolus of $350 \mu \mathrm{g} / \mathrm{kg}$ is proposed followed by an intravenous infusion of $25 \mu \mathrm{g} / \mathrm{kg} / \mathrm{min}$ adapted to maintain an ACT between 300 and 450 seconds.
The removal of the desilet will be performed two or four hours after stopping bivalirudin or argatroban, respectively.

\section{HIT and severe renal failure}

In the case of renal replacement therapy (RRT), two situations can be distinguished.

The patient is being treated with argatroban

Renal failure has little influence on the pharmacokinetics of argatroban, as does RRT. RRT is started without an argatroban bolus, continuing infusion and biological monitoring.

\section{The patient is not treated with argatroban}

Teams mastering this technique can consider the realisation of RRT with citrate. Argatroban can also be the anticoagulant used for circuit anticoagulation. It is then administered as a bolus $(100 \mu \mathrm{g} /$ $\mathrm{kg}$ for continuous RRT or $250 \mu \mathrm{g} / \mathrm{kg}$ for intermittent haemodialysis) followed by a continuous infusion according to its conventional regimen (see question 7). The infusion is stopped one hour before the end of the session [63].

Danaparoid accumulates in renal failure. Its use for continuous RRT is delicate, with very high doses proposed in this context of risk of bleeding. In case of intermittent haemodialysis, the danaparoid SPC proposes the following protocol: bolus of $3750 \mathrm{U}$ (2500 $\mathrm{U}$ if weight $<55 \mathrm{~kg}$ ) before the first two sessions and $3000 \mathrm{U}$ (2000 $\mathrm{U}$ if weight $<55 \mathrm{~kg}$ ) [88].

\section{HIT and pregnancy}

Pregnancy is very rarely complicated by HIT. Danaparoid sodium, which does not cross the placenta, has been the most commonly used anticoagulant in this context [99] and is therefore recommended as a first-line treatment, particularly by the British [3]. Argatroban is contraindicated, as are DOACs.

If danaparoid is not available, fondaparinux is an option that can also be proposed [3] although there is little data $[100,101]$.

\section{HIT in children}

The risk of HIT is a priori considered to be lower in children with lower circulating levels of PF4 [102]. For example, a recent study found an HIT prevalence of $0.058 \%$ in a single paediatric centre [103]. The same study identified 12 children with suspected HIT, most of whom were hospitalised in surgery and treated with UFH.

In cardiac surgery, the development of anti-PF4 heparin antibodies in postoperative care can affect 3 to more than 50\% of operated children, with the incidence of immunisation increasing with the number of procedures [104]. But, as in adults, HIT will affect only a small proportion of immunised children with a long overestimated risk, but which has recently been assessed as intermediate, equal to $0.33 \%$ [105]. Therefore, as in adults, platelet count monitoring should be maintained in all children treated with UFH regardless of age and underlying context.

Regarding the diagnosis, clinical data with the 4T score and biological analyses must be combined to exclude or affirm HIT.

For the treatment, danaparoid sodium and argatroban can be used, taking into account, as in adults, hepatic and renal functions to select the drug with the lowest risk of overdose [106-108]. A small series reported the history of 4 infants aged 3 to 7 months with HIT following cardiac surgery, and treated with low doses of argatroban, monitored with TCA and ACT [106]. Large variations in doses and test effects were noted and 3 out of 4 children survived. 


\section{Question 12: What prevention can be used to avoid the occurrence of HIT or recurrence?}

\section{Proposal \# 39}

It is proposed that a haemostasis consultation be performed within 3 months of the diagnosis of HIT and that a card attesting this complication, specifying the results of the biological tests and recommending the exclusion of all heparin treatment be given to the patient.

(STRONG AGREEMENT)

\section{Proposal \# 40}

In case of a history of HIT, it is proposed to prescribe an oral anticoagulant (VKA or DOAC) or fondaparinux when a prophylactic or curative anticoagulation is indicated. Argatroban, bivalirudin and danaparoid should only be considered in cases where oral anticoagulants and fondaparinux are contraindicated.

(STRONG AGREEMENT)

\section{Rationale}

The primary prevention of HIT is mainly ensured by three types of measures:

- prescribe heparins only in validated indications;

- preferably prescribe oral anticoagulants, or as a second-line choice LMWH, in validated indications, avoiding as much as possible the use of UFH;

- limit the duration of heparin treatment to the shortest possible time ( $<4-5$ days) with early relay with oral anticoagulant.

The secondary prevention, and therefore of a recurrence of HIT, is based on three measures:

- establish for each patient who has had an HIT a medical certificate or card attesting to the reality of this history and the results of the biological tests that led to the diagnosis. Permanent wearing of this document by the patient is particularly important within 3 months of HIT because the risk of recurrence is higher during this period if there is new exposure to heparin, although it is not constant [10];

- perform a sensitive biological test (ELISA) to test the absence or persistence of PF4-specific antibodies in the blood before any further exposure to heparin, as a high titre exposes the patient to a risk of HIT recurrence [109];

- preferably prescribe an oral anticoagulant (VKA or DOAC, dabigatran), or fondaparinux in case of a history of HIT, respecting the validated indications. Failing this in very specific situations for which no other option is possible, a non-heparinic injectable anticoagulant, danaparoid sodium or argatroban, will be used. It should be noted, however, that the risk of HIT recurrence after re-exposure of the patient to heparin is uncertain or even considered quite low, especially if LMWH is administered. It is higher if the patient is exposed to UFH for more than 5 days [110] and in the context of cardiac surgery [109].

\section{Disclosure of interest}

P. Albaladejo reports conflicts of interest with Bayer, Pfizer-BMS, Sanofi, Aspen, and Portola.

N. Blais, D. Lasne, T. Lecompte, S. Roullet, S. Susen, A. Vincentelli declare that they have no competing interest.
A. Godier has received consulting fees and non-financial support from Bayer Healthcare, BMS/Pfizer, Boehringer-Ingelheim, Sanofi-Adventis, LFB, CSL-Behring, and Octapharma.

Y. Gruel reports consulting and/or travel fees from Aguettant, LFB, and Sanofi; grant from Stago.

G. Le Gal is co-investigator on grants received from Portola Pharmaceuticals, Boehringer-Ingelheim, Pfizer, Bristol-Myers Squibb, LEO Pharma, Daiichi Sankyo, and Bayer. He has received speaker honoraria (not taken as salary) from Bayer, Pfizer, LEO Pharma, Sanofi, and bioMérieux.

E. de Maistre reports conflicts of interest with Stago, BoehringerIngelheim, Pfizer, BMS, and Bayer (advisory boards).

F. Mullier reports institutional fees from Stago, Werfen, Nodia, Sysmex and Bayer. He also reports speaker fees from Boehringer-Ingelheim, Bayer Healthcare, Bristol-Myers Squibb-Pfizer, Stago, Werfen and Aspen all outside the submitted work.

C. Pouplard reports a grant from Stago.

\section{References}

[1] Société française d'anesthésie et de réanimation. Thrombopénie induite par l'héparine. Ann Fr Anesth Reanim 2003;22:150-9.

[2] Linkins LA, Dans AL, Moores LK, Bona R, Davidson BL, Schulman S, et al. Treatment and prevention of heparin-induced thrombocytopenia: antithrombotic therapy and prevention of thrombosis, 9th ed: American College of Chest Physicians Evidence-Based Clinical Practice Guidelines. Chest 2012;141(2 Suppl.). e495S-e530S.

[3] Watson H, Davidson S, Keeling D. Guidelines on the diagnosis and management of heparin-induced thrombocytopenia: second edition. $\mathrm{Br} \mathrm{J}$ Haematol 2012;159(5):528-40

[4] Cuker A, Arepally GM, Chong BH, Cines DB, Greinacher A, Gruel Y, et al. American Society of Hematology 2018. Guidelines for management of venous thromboembolism: heparin-induced thrombocytopenia. Blood Adv 2018;2(22):3360-92

[5] Amiral J, Bridey F, Dreyfus M, Vissac A, Fressinaud E, Wolf M, et al. Platelet factor 4 complexed to heparin is the target for antibodies generated in heparin-induced thrombocytopenia. Thromb Haemost 1992;68(1):95-6.

[6] Greinacher A. Clinical practice. Heparin-induced thrombocytopenia. N Engl ] Med 2015;373(3):252-61.

[7] Arepally GM. Heparin-induced thrombocytopenia. Blood 2017;129(21): 2864-72.

[8] Pouplard C, Iochmann S, Renard B, Herault O, Colombat P, Amiral J, et al Induction of monocyte tissue factor expression by antibodies to heparinplatelet factor 4 complexes developed in heparin-induced thrombocytopenia. Blood 2001:97(10):3300-2

[9] Warkentin TE, Kelton JG. A 14-year study of heparin-induced thrombocytopenia. Am J Med 1996;101(5):502-7.

[10] Warkentin TE, Kelton JG. Temporal aspects of heparin-induced thrombocytopenia. N Engl J Med 2001;344(17):1286-92.

[11] Warkentin TE. Fondaparinux: does it cause HIT? Can it treat HIT? Expert Rev Hematol 2010;3(5):567-81.

[12] Prandoni P, Siragusa S, Girolami B, Fabris F. The incidence of heparin-induced thrombocytopenia in medical patients treated with low-molecular-weight heparin: a prospective cohort study. Blood 2005;106(9):3049-54.

[13] Kato S, Takahashi K, Ayabe K, Samad R, Fukaya E, Friedmann P, et al. Heparininduced thrombocytopenia: analysis of risk factors in medical inpatients. $\mathrm{Br}$ ] Haematol 2011;154(3):373-7.

[14] Greer IA, Nelson-Piercy C. Low-molecular-weight heparins for thromboprophylaxis and treatment of venous thromboembolism in pregnancy: a systematic review of safety and efficacy. Blood 2005;106(2):401-7.

[15] Martel N, Lee J, Wells PS. Risk for heparin-induced thrombocytopenia with unfractionated and low-molecular-weight heparin thromboprophylaxis: a meta-analysis. Blood 2005:106(8):2710-5.

[16] Junqueira DR, Zorzela LM, Perini E. Unfractionated heparin versus low molecular weight heparins for avoiding heparin-induced thrombocytopenia in postoperative patients. Cochrane Database Syst Rev 2017:4:CD007557.

[17] Lubenow N, Hinz P, Thomaschewski S, Lietz T, Vogler M, Ladwig A, et al. The severity of trauma determines the immune response to PF4/heparin and the frequency of heparin-induced thrombocytopenia. Blood 2010;115(9):1797803.

[18] Bloemen A, Testroote MJ, Janssen-Heijnen ML, Janzing HM. Incidence and diagnosis of heparin-induced thrombocytopenia (HIT) in patients with traumatic injuries treated with unfractioned or low-molecular-weight heparin: a literature review. Injury 2012;43(5):548-52.

[19] Craik JD, Cobb AG. Heparin-induced thrombocytopenia following hip and knee arthroplasty. Br J Haematol 2013;161(2):255-61.

[20] Pouplard C, May MA, Iochmann S, Amiral J, Vissac AM, Marchand M, et al. Antibodies to platelet factor 4 - Heparin after cardiopulmonary bypass in patients anticoagulated with unfractionated heparin or a low-molecularweight heparin - Clinical implications for heparin-induced thrombocytopenia. Circulation 1999:99(19):2530-6.

[21] Pouplard C, May MA, Regina S, Marchand M, Fusciardi J, Gruel Y. Changes in platelet count after cardiac surgery can effectively predict the development 
of pathogenic heparin-dependent antibodies. Br J Haematol 2005;128(6): 837-41.

[22] Wu W, Merriman K, Nabaah A, Seval N, Afshar-Kharghan V, Yeung SC Heparin-induced thrombocytopenia among patients of a comprehensive cancer center. SAGE Open Med Case Rep 2014;2 [2050313X14533945].

[23] Warkentin TE, Sheppard JA, Horsewood P, Simpson PJ, Moore JC, Kelton JG. Impact of the patient population on the risk for heparin-induced thrombocytopenia. Blood 2000;96(5):1703-8.

[24] Pishko AM, Cuker A, Arepally GM. Heparin-induced thrombocytopenia in cardiac surgery patients heparin-induced thrombocytopenia. Semin Thromb Hemost 2017;43(7):691-8.

[25] Girolami B, Prandoni P, Stefani PM, Tanduo C, Sabbion P, Eichler P, et al. The incidence of heparin-induced thrombocytopenia in hospitalized medical patients treated with subcutaneous unfractionated heparin: a prospective cohort study. Blood 2003;101(8):2955-9.

[26] Lee DH, Warkentin TE. Frequency of heparin-induced thrombocytopenia. In: Warkentin TE, Greinacher A, editors. Heparin-induced thrombocytopenia. 3rd ed., New York-Basel: Marcel Dekker Inc; 2004. p. 107-48.

[27] Smythe MA, Koerber JM, Mattson JC. The incidence of recognized heparininduced thrombocytopenia in a large, tertiary care teaching hospital. Chest 2007;131(6):1644-9.

[28] Kimmoun A, Oulehri W, Sonneville R, Grisot PH, Zogheib E, Amour J, et al. Prevalence and outcome of heparin-induced thrombocytopenia diagnosed under veno-arterial extracorporeal membrane oxygenation: a retrospective nationwide study. Intensive Care Med 2018.

[29] Laverdure F, Louvain-Quintard V, Kortchinsky T, Rezaiguia-Delclaux S, Imber A, Stephan F. PF4-heparin antibodies during ECMO: incidence, course, and outcomes. Intensive Care Med 2016;42(6):1082-3.

[30] Pollak U. Heparin-induced thrombocytopenia complicating extracorporeal membrane oxygenation support in pediatric patients: review of the literature and alternative anticoagulants. Perfusion 2018;33(1_suppl.):7-17.

[31] Lillo-Le Louet A, Boutouyrie P, Alhenc-Gelas M, Le Beller C, Gautier I, Aiach M et al. Diagnostic score for heparin-induced thrombocytopenia after cardiopulmonary bypass. J Thromb Haemost 2004;2(11):1882-8.

[32] Gruel Y, Pouplard C, Nguyen P, Borg JY, Derlon A, Juhan-Vague I, et al. Biological and clinical features of low-molecular-weight heparin-induced thrombocytopenia. Br J Haematol 2003;121(5):786-92.

[33] Tardy B, Tardy-Poncet B, Fournel P, Venet C, Jospe R, Dacosta A. Lower limbs veins should be systematically explored in patients with isolated heparin-induced thrombocytopenia. Thromb Haemostas 1999;82(3):11992000.

[34] Warkentin TE, Elavathil LJ, Hayward CP, Johnston MA, Russett JI, Kelton JG. The pathogenesis of venous limb gangrene associated with heparin-induced thrombocytopenia. Ann Intern Med 1997;127(9):804-12.

[35] Warkentin TE, Sikov WM, Lillicrap DP. Multicentric warfarin-induced skin necrosis complicating heparin-induced thrombocytopenia. Am J Hemato 1999;62(1):44-8.

[36] Fontana P, Bodmer A, Gruel Y, Boehlen F, Janer V, Kaya G, et al. Skin necrosis is a clinical manifestation of low-molecular weight heparin-induced thrombocytopenia. Thromb Haemost 2004;91(1):196-7.

[37] Schindewolf M, Kroll $H$, Ackermann $H$, Garbaraviciene J, Kaufmann $R$, Boehncke WH, et al. Heparin-induced non-necrotizing skin lesions: rarely associated with heparin-induced thrombocytopenia. J Thromb Haemost 2010;8(7):1486-91.

[38] Thachil J, Warkentin TE. How do we approach thrombocytopenia in critically ill patients? Br J Haematol 2017;177(1):27-38.

[39] Arnold DM, Kukaswadia S, Nazi I, Esmail A, Dewar L, Smith JW, et al. A systematic evaluation of laboratory testing for drug-induced immune thrombocytopenia. J Thromb Haemost 2013;11(1):169-76.

[40] Perunicic J, Antonijevic NM, Miljic P, Djordjevic V, Mikovic D, Kovac M, et al. Clinical challenge: heparin-induced thrombocytopenia type II (HIT II) or pseudo-HIT in a patient with antiphospholipid syndrome. J Thromb Thrombolysis 2008;26(2):142-6.

[41] Lo GK, Juhl D, Warkentin TE, Sigouin CS, Eichler P, Greinacher A. Evaluation of pretest clinical score (4 T's) for the diagnosis of heparin-induced thrombocytopenia in two clinical settings. J Thromb Haemost 2006;4(4):759-65.

[42] Gruel Y, Pouplard C. Post-operative platelet count profile: the most reliable tool for identifying patients with true heparin-induced thrombocypenia after cardiac surgery. J Thromb Haemost 2010;8(1):27-9.

[43] Linkins LA, Bates SM, Lee AY, Heddle NM, Wang G, Warkentin TE. Combination of 4Ts score and PF4/H-PaGIA for diagnosis and management of heparininduced thrombocytopenia: prospective cohort study. Blood 2015;126(5): 597-603.

[44] Warkentin TE, Greinacher A, Gruel Y, Aster RH, Chong BH. Laboratory testing for heparin-induced thrombocytopenia: a conceptual framework and implications for diagnosis. J Thromb Haemost 2011;9(12):2498-500.

[45] Nagler M, Bachmann LM, ten Cate H, ten Cate-Hoek A. Diagnostic value of immunoassays for heparin-induced thrombocytopenia: a systematic review and meta-analysis. Blood 2016;127(5):546-57.

[46] Husseinzadeh HD, Gimotty PA, Pishko AM, Buckley M, Warkentin TE, Cuker A. Diagnostic accuracy of IgG-specific versus polyspecific enzyme-linked immunoassays in heparin-induced thrombocytopenia: a systematic review and meta-analysis. J Thromb Haemost 2017;15(6):1203-12.

[47] Whitlatch NL, Kong DF, Metjian AD, Arepally GM, Ortel TL. Validation of the high-dose heparin confirmatory step for the diagnosis of heparin-induced thrombocytopenia. Blood 2010;116(10):1761-6.
[48] Althaus K, Strobel U, Warkentin TE, Greinacher A. Combined use of the high heparin step and optical density to optimize diagnostic sensitivity and specificity of an anti-PF4/heparin enzyme-immunoassay. Thromb Res 2011;128(3):256-60.

[49] Warkentin TE, Sheppard JI. No significant improvement in diagnostic specificity of an anti-PF4/polyanion immunoassay with use of high heparin confirmatory procedure. J Thromb Haemost 2006;4(1):281-2.

[50] Minet V, Dogne JM, Mullier F. Functional assays in the diagnosis of heparininduced thrombocytopenia: a review. Molecules 2017:22(4):617.

[51] Morel-Kopp MC, Mullier F, Gkalea V, Bakchoul T, Minet V, Elalamy I, et al. Heparin-induced multi-electrode aggregometry method for heparin-induced thrombocytopenia testing: communication from the SSC of the ISTH. J Thromb Haemost 2016;14(12):2548-52.

[52] Cuker A. Clinical and laboratory diagnosis of heparin-induced thrombocytopenia: an integrated approach. Semin Thromb Hemost 2014;40(1):106-14.

[53] Regnault V, De Maistre E, Carteaux JP, Gruel Y, Nguyen P, Tardy B, et al. Platelet activation induced by human antibodies to interleukin-8. Blood 2003;101(4):1419-21.

[54] Chong BH, Gallus AS, Cade JF, Magnani H, Manoharan A, Oldmeadow M, et al. Prospective randomised open-label comparison of danaparoid with dextran 70 in the treatment of heparin-induced thrombocytopaenia with thrombosis: a clinical outcome study. Thromb Haemost 2001;86(5):1170-5.

[55] Farner B, Eichler P, Kroll H, Greinacher A. A comparison of danaparoid and lepirudin in heparin-induced thrombocytopenia. Thromb Haemost 2001;85(6):950-7.

[56] Lubenow N, Warkentin TE, Greinacher A, Wessel A, Sloane DA, Krahn EL, et al. Results of a systematic evaluation of treatment outcomes for heparin-induced thrombocytopenia in patients receiving danaparoid, ancrod, and/or coumarin explain the rapid shift in clinical practice during the 1990s. Thromb Res 2006;117(5):507-15.

[57] Magnani HN, Gallus A. Heparin-induced thrombocytopenia (HIT). A report of 1478 clinical outcomes of patients treated with danaparoid (Orgaran) from 1982 to mid-2004. Thromb Haemost 2006;95(6):967-81.

[58] Tardy-Poncet B, Wolf M, Lasne D, Bauters A, Ffrench P, Elalamy I, et al. Danaparoid cross-reactivity with heparin-induced thrombocytopenia antibodies: report of 12 cases. Intensive Care Med 2009;35(8):1449-53.

[59] Lewis BE, Wallis DE, Berkowitz SD, Matthai WH, Fareed J, Walenga JM, et al. Argatroban anticoagulant therapy in patients with heparin-induced thrombocytopenia. Circulation 2001;103(14):1838-43.

[60] Lewis BE, Wallis DE, Leya F, Hursting MJ, Kelton JG. Argatroban anticoagulation in patients with heparin-induced thrombocytopenia. Arch Intern Med 2003;163(15):1849-56.

[61] Tardy-Poncet B, Nguyen P, Thiranos JC, Morange PE, Biron-Andreani C, Gruel $Y$, et al. Argatroban in the management of heparin-induced thrombocytopenia: a multicenter clinical trial. Crit Care 2015;19:396.

[62] Swan SK, Hursting MJ. The pharmacokinetics and pharmacodynamics of argatroban: effects of age, gender, and hepatic or renal dysfunction. Pharmacotherapy 2000;20(3):318-29.

[63] Alatri A, Armstrong AE, Greinacher A, Koster A, Kozek-Langenecker SA, Lance $\mathrm{MD}$, et al. Results of a consensus meeting on the use of argatroban in patients with heparin-induced thrombocytopenia requiring antithrombotic therapy - a European Perspective. Thromb Res 2012;129(4):426-33.

[64] Rozec B, Boissier E, Godier A, Cinotti R, Stephan F, Blanloeil Y. [Argatroban, a new antithrombotic treatment for heparin-induced thrombocytopenia application in cardiac surgery and in intensive care]. Ann Fr Anesth Reanim 2014;33(9-10):514-23.

[65] Godier A, Flaujac C, Horellou MH, De Mesmay M, Becanne X, Parisot M, et al. Argatroban and renal replacement therapy in a morbidly obese patient with heparin-induced thrombocytopenia: a case report. Thromb Res 2010;126(2): e141-3.

[66] Guy S, Kitchen S, Maclean R, Van Veen JJ. Limitation of the activated partial thromboplastin time as a monitoring method of the direct thrombin inhibitor argatroban. Int J Lab Hematol 2015;37(6):834-43.

[67] Guy S, Kitchen S, Van Veen JJ. Further evidence of the limitations of activated partial thromboplastin time to monitor argatroban. $\mathrm{Br} \mathrm{J}$ Haematol 2018;180(4):594-7

[68] Warkentin TE, Koster A. Bivalirudin: a review. Expert Opin Pharmacother 2005;6(8):1349-71

[69] Kang M, Alahmadi M, Sawh S, Kovacs MJ, Lazo-Langner A. Fondaparinux for the treatment of suspected heparin-induced thrombocytopenia: a propensity score-matched study. Blood 2015;125(6):924-9.

[70] Schindewolf M, Steindl J, Beyer-Westendorf J, Schellong S, Dohmen PM, Brachmann J, et al. Use of fondaparinux off-label or approved anticoagulants for management of heparin-induced thrombocytopenia. J Am Coll Cardiol 2017;70(21):2636-48.

[71] Aljabri A, Huckleberry Y, Karnes JH, Gharaibeh M, Kutbi HI, Raz Y, et al. Costeffectiveness of anticoagulants for suspected heparin-induced thrombocytopenia in the United States. Blood 2016;128(26):3043-51.

[72] Cegarra-Sanmartin V, Gonzalez-Rodriguez R, Paniagua-Iglesias P, Santamaria-Ortiz A, Cueva LF, Galan-Serrano J, et al. Fondaparinux as a safe alternative for managing heparin-induced thrombocytopenia in postoperative cardiac surgery patients. J Cardiothorac Vasc Anesth 2014;28(4):1008-12.

[73] Krauel K, Hackbarth C, Furll B, Greinacher A. Heparin-induced thrombocytopenia: in vitro studies on the interaction of dabigatran, rivaroxaban, and lowsulfated heparin, with platelet factor 4 and anti-PF4/heparin antibodies. Blood 2012;119(5):1248-55. 
[74] Sharifi M, Bay C, Vajo Z, Freeman W, Sharifi M, Schwartz F. New oral anticoagulants in the treatment of heparin-induced thrombocytopenia. Thromb Res 2015;135(4):607-9.

[75] Linkins LA, Warkentin TE, Pai M, Shivakumar S, Manji RA, Wells PS, et al. Rivaroxaban for treatment of suspected or confirmed heparin-induced thrombocytopenia study. J Thromb Haemost 2016;14(6):1206-10.

[76] Ong SY, Chin YA, Than H, Tan CW, Yap ES, Wong WH, et al. Rivaroxaban for heparin-induced thrombocytopenia: adding to the evidence. Ann Hematol 2017;96(3):525-7.

[77] Warkentin TE, Pai M, Linkins LA. Direct oral anticoagulants for treatment of HIT: update of Hamilton experience and literature review. Blood 2017;130(9):1104-13.

[78] Irani M, Siegal E, Jella A, Aster R, Padmanabhan A, Bakchoul T, et al. Use of intravenous immunoglobulin $G$ to treat spontaneous heparin-induced thrombocytopenia Drug-associated thrombocytopenia. Transfusion 2019;59(3):931-4.

[79] Mohanty E, Nazir S, Sheppard JI, Forman DA, Warkentin TE. High-dose intravenous immunoglobulin to treat spontaneous heparin-induced thrombocytopenia syndrome. J Thromb Haemost 2019;17(5):841-4.

[80] Padmanabhan A, Jones CG, Pechauer SM, Curtis BR, Bougie DW, Irani MS, et al. IVIg for treatment of severe refractory heparin-induced thrombocytopenia. Chest 2017;152(3):478-85.

[81] Arcinas LA, Manji RA, Hrymak C, Dao V, Sheppard JI, Warkentin TE. Autoimmune heparin-induced thrombocytopenia and venous limb gangrene after aortic dissection repair: in vitro and in vivo effects of intravenous immunoglobulin. Transfusion 2019;59(6):1924-33.

[82] Jaben EA, Torloni AS, Pruthi RK, Winters JL. Use of plasma exchange in patients with heparin-induced thrombocytopenia: a report of two cases and a review of the literature. J Clin Apher 2011;26(4):219-24.

[83] Goel R, Ness PM, Takemoto CM, Krishnamurti L, King KE, Tobian AA. Platelet transfusions in platelet consumptive disorders are associated with arterial thrombosis and in-hospital mortality. Blood 2015;125(9):1470-6.

[84] Albaladejo P, Bonhomme F, Blais N, Collet JP, Faraoni D, Fontana P, et al. Management of direct oral anticoagulants in patients undergoing elective surgeries and invasive procedures: updated guidelines from the French Working Group on Perioperative Hemostasis (GIHP) - September 2015. Anaesth Crit Care Pain Med 2017;36(1):73-6.

[85] Vayne C, Guery EA, Kizlik-Masson C, Rollin J, Bauters A, Gruel Y, et al. Beneficial effect of exogenous platelet factor 4 for detecting pathogenic heparin-induced thrombocytopenia antibodies. Br J Haematol 2017;179(5): 811-9.

[86] Rehfeldt KH, Barbara DW. Cardiopulmonary bypass without heparin. Semin Cardiothorac Vasc Anesth 2016;20(1):40-51.

[87] Koster A, Faraoni D, Levy JH. Argatroban and bivalirudin for perioperative anticoagulation in cardiac surgery. Anesthesiology 2018;128(2):390-400.

[88] Wadia Y, Cooper JR, Bracey AW, Pinto K, Frazier OH. Intraoperative anticoagulation management during cardiac transplantation for a patient with heparin-induced thrombocytopenia and a left ventricular assist device. Tex Heart Inst J 2008;35(1):62-5.

[89] Welsby IJ, Um J, Milano CA, Ortel TL, Arepally G. Plasmapheresis and heparin reexposure as a management strategy for cardiac surgical patients with heparin-induced thrombocytopenia. Anesth Analg 2010;110(1):30-5.

[90] Koster A, Kukucka M, Bach F, Meyer O, Fischer T, Mertzlufft F, et al. Anticoagulation during cardiopulmonary bypass in patients with heparin-induced thrombocytopenia type II and renal impairment using heparin and the platelet glycoprotein IIb-IIIa antagonist tirofiban. Anesthesiology 2001;94(2):245-51

[91] Gernhofer YK, Ross M, Khoche S, Pretorius V. The use of cangrelor with heparin for left ventricular assist device implantation in a patient with acute heparin-induced thrombocytopenia. J Cardiothorac Surg 2018;13(1):30.

[92] Seider S, Ross M, Pretorius V, Maus T. The use of cangrelor and heparin for anticoagulation in a patient requiring pulmonary thromboendarterectomy surgery with suspected heparin-induced thrombocytopenia. J Cardiothorac Vasc Anesth 2019;33(4):1050-3.
[93] Martin ME, Kloecker GH, Laber DA. Argatroban for anticoagulation during cardiac surgery. Eur J Haematol 2007:78(2):161-6.

[94] Czosnowski QA, Finks SW, Rogers KC. Bivalirudin for patients with heparininduced thrombocytopenia undergoing cardiovascular surgery. Ann Pharmacother 2008;42(9):1304-9.

[95] Joseph L, Casanegra AI, Dhariwal M, Smith MA, Raju MG, Militello MA, et al. Bivalirudin for the treatment of patients with confirmed or suspected heparin-induced thrombocytopenia. J Thromb Haemost 2014;12(7):1044-53.

[96] Lewis BE, Matthai Jr WH, Cohen M, Moses JW, Hursting MJ, Leya F. Argatroban anticoagulation during percutaneous coronary intervention in patients with heparin-induced thrombocytopenia. Catheter Cardiovasc Interv 2002;57(2):177-84

[97] Mahaffey KW, Lewis BE, Wildermann NM, Berkowitz SD, Oliverio RM, Turco MA, et al. The anticoagulant therapy with bivalirudin to assist in the performance of percutaneous coronary intervention in patients with heparininduced thrombocytopenia (ATBAT) study: main results. J Invasive Cardiol 2003;15(11):611-6.

[98] Lee MS, Liao H, Yang T, Dhoot J, Tobis J, Fonarow G, et al. Comparison of bivalirudin versus heparin plus glycoprotein IIb/IIIa inhibitors in patients undergoing an invasive strategy: a meta-analysis of randomized clinical trials. Int J Cardiol 2011;152(3):369-74.

[99] Lindhoff-Last E, Kreutzenbeck HJ, Magnani HN. Treatment of 51 pregnancies with danaparoid because of heparin intolerance. Thromb Haemost 2005;93(1):63-9.

[100] Chaudhary RK, Nepal C, Khanal N, Pathak R, Giri S, Bhatt VR. Management and outcome of heparin-induced thrombocytopenia in pregnancy: a systematic review. Cardiovasc Hematol Agents Med Chem 2015;13(2):92-7.

[101] De Carolis S, di Pasquo E, Rossi E, Del Sordo G, Buonomo A, Schiavino D, et al. Fondaparinux in pregnancy: could it be a safe option? A review of the literature. Thromb Res 2015;135(6):1049-51.

[102] Newall F, Johnston L, Ignjatovic V, Summerhayes R, Monagle P. Age-related plasma reference ranges for two heparin-binding proteins - vitronectin and platelet factor 4. Int J Lab Hematol 2009;31(6):683-7.

[103] Obeng EA, Harney KM, Moniz T, Arnold A, Neufeld EJ, Trenor 3rd CC. Pediatric heparin-induced thrombocytopenia: prevalence, thrombotic risk, and application of the 4Ts scoring system. J Pediatr 2015;166(1):144-50.

[104] Mullen MP, Wessel DL, Thomas KC, Gauvreau K, Neufeld EJ, McGowan Jr FX, et al. The incidence and implications of anti-heparin-platelet factor 4 antibody formation in a pediatric cardiac surgical population. Anesth Analg 2008;107(2):371-8

[105] Avila ML, Shah V, Brandao LR. Systematic review on heparin-induced thrombocytopenia in children: a call to action. J Thromb Haemost 2013;11(4):660-9.

[106] Abdillah JN, Hu Q, Chen X, Chen X, Zhou W, Luo W, et al. Heparin-induced thrombocytopenia in infants after heart surgery. Thorac Cardiovasc Surg 2018;67(1):21-7.

[107] Risch L, Fischer JE, Herklotz R, Huber AR. Heparin-induced thrombocytopenia in paediatrics: clinical characteristics, therapy and outcomes. Intensive Care Med 2004;30(8):1615-24

[108] Severin T, Zieger B, Sutor AH. Anticoagulation with recombinant hirudin and danaparoid sodium in pediatric patients. Semin Thromb Hemost 2002;28(5): 447-54.

[109] Warkentin TE, Sheppard JA. Serological investigation of patients with a previous history of heparin-induced thrombocytopenia who are reexposed to heparin. Blood 2014;123(16):2485-93.

[110] Gruel Y, Lang M, Darnige L, Pacouret G, Dreyfus X, Leroy J, et al. Fatal effect of re-exposure to heparin after previous heparin-associated thrombocytopenia and thrombosis. Lancet 1990;336(8722):1077-8.

[111] Srinivasan AF, Rice L, Bartholomew JR, Rangaswamy C, La Perna L, Thompson $\mathrm{JE}$, et al. Warfarin-induced skin necrosis and venous limb gangrene in the setting of heparin-induced thrombocytopenia. Arch Intern Med 2004;164(1): $66-70$.

[112] Davis KA, Davis DO. Direct acting oral anticoagulants for the treatment of suspected heparin-induced thrombocytopenia. Eur J Haematol 2017;99(4): 332-5. 